\title{
EXPLORING DIFFERENT APPROACHES UTILISED IN MUSIC THERAPY PRACTICE WITH A WIDE RANGE OF CLIENTS IN VARIOUS CLINICAL SETTINGS
}

\author{
by \\ Wei-kai Shyu \\ B.MUS., University of Auckland, 2015 \\ A thesis submitted in partial fulfillment of the requirements for the degree \\ MASTER OF MUSIC THERAPY \\ Department of Music Therapy \\ New Zealand School of Music \\ VICTORIA UNIVERSITY OF WELLINGTON \\ Wellington, New Zealand
}



The Victoria University of Wellington Human Ethics Committee has granted ethical approval for this research project under the generic template approved for NZSM526 Casework and Research (Ethics Approval: 22131 - 04/04/2017) 


\begin{abstract}
Diversity of practice demands diversity in approaches. This explorative qualitative research study was conducted to help me understand and improve my practice with a wide range of client populations in various clinical settings. Clinical work took place over eight months at a specialised clinic working with mainly young children and adolescents with intellectual/developmental disabilities. Clinical work also took place as part of an outreach service at a healthcare facility for young adults with various neurological disabilities. Musiccentered music therapy, humanistic music therapy, behavioural music therapy, and psychodynamic music therapy approaches influenced this work. The methodology I employed for the research was secondary analysis of data. This involved thematic analysis (both inductive and deductive) of my clinical notes and reflective journal, to identify and draw out themes pertaining to my research question. Clinical data has been used to illustrate the findings, and a clinical vignette is included to illustrate the approaches utilised in clinical practice. The data revealed underlying humanistic frameworks in most of my clinical practice, but also indicated that I draw on other approaches in certain contexts. This research provides a descriptive qualitative account of one student's music therapy practice in New Zealand. The example may provide some insight into the potential benefits of utilizing various approaches when working with clients with varying needs.
\end{abstract}




\section{Acknowledgements}

Writing this exegesis has had a significant impact on my academic and personal growth. I would like to reflect on the people who have supported and helped me so much throughout this period.

\section{Thank you,}

Mom and Dad, for your unconditional support and sage advice, and not to forget, providing me home-cooked meals when I was out here questioning my sanity, bone-weary and malnourished.

Dr. Daphne Rickson, for your wise counsel and patience; for passing down your wealth of knowledge and providing me a very enriched postgraduate experience I shall forever embrace.

My clinical supervisor, co-therapists, mentors, and my dear friends at the facility in which I have come to call my family. I am infinitely grateful to you, for you have kept the spirit of music therapy alive in me. I am deeply inspired by each one of you.

Aunt Tricia, for your ongoing prudence, sagacity and warmth throughout my entire journey of academia...well, basically my entire life. You will always be my role model.

Principal Brown, for your optimistic outlook on life and reminding me of the things that are truly important.

My breathers, for preventing me from going into perpetual hibernation. I've enjoyed our latenight walks on the beach.

My classmates, for the endless laughter, genius, and music-making.

MayLing, for your caring, loving and compassionate soul and always being there for me along the way. You are the umbrella to my rainy days. 


\section{Table of Contents}

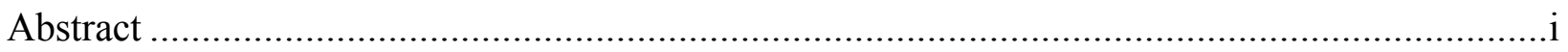

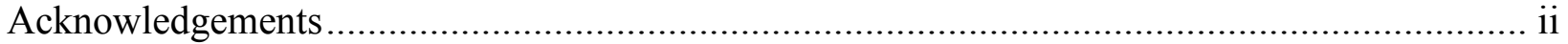

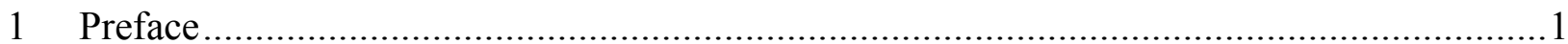

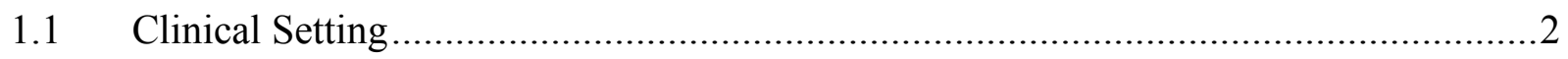

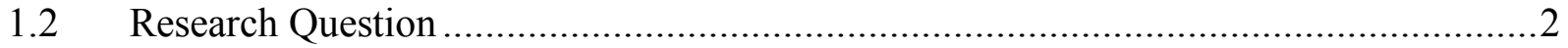

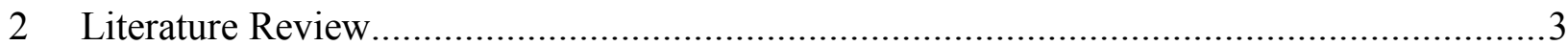

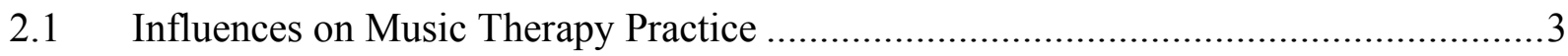

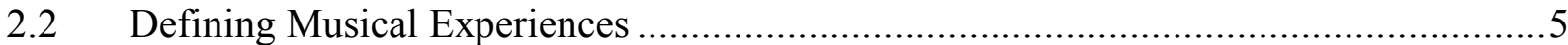

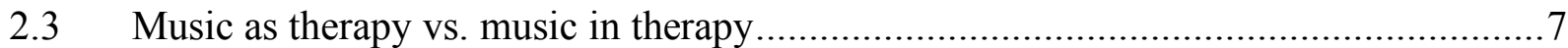

2.4 Approaches and Perspectives in Music Therapy Practice ……………………...........

2.5 Music-centered Approaches in Music Therapy .......................................................

2.6 Behavioural Approaches in Music Therapy.......................................................... 10

2.7 Psychodynamic Approaches in Music Therapy .....................................................11

2.8 Humanistic Approaches in Music Therapy............................................................ 12

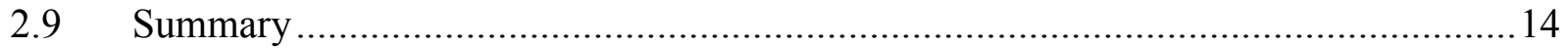

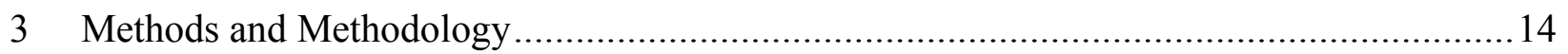

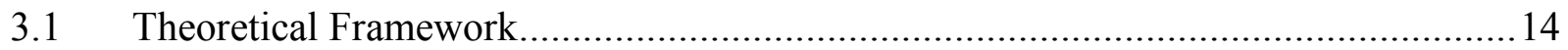

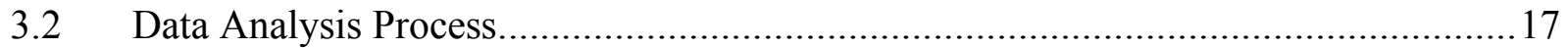

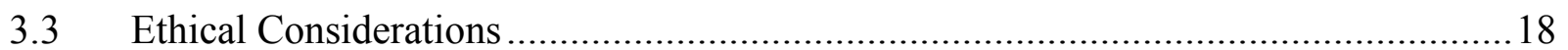

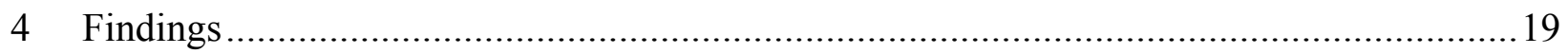

4.1 Music-centered Approach .................................................................................19

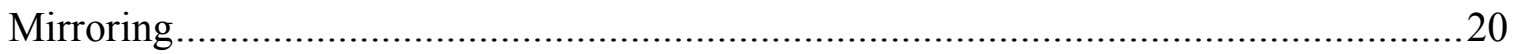

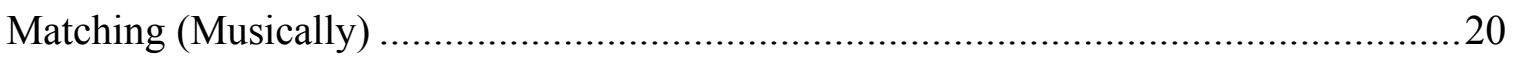

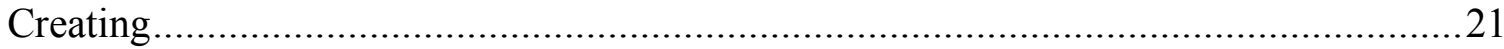

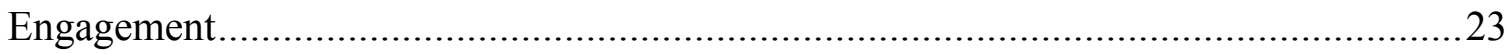

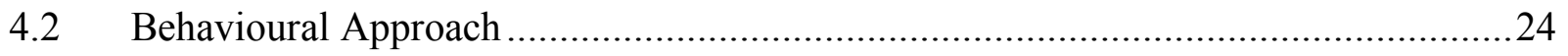

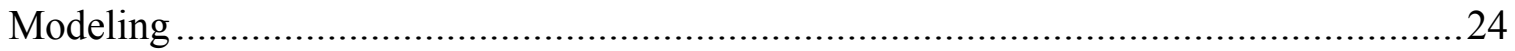

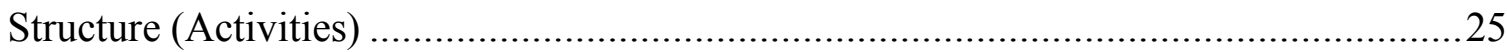

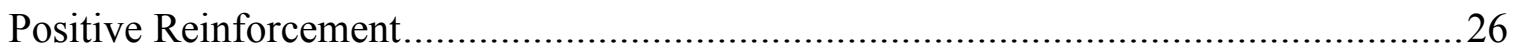




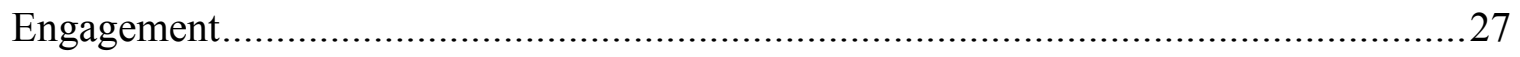

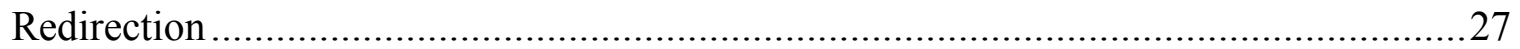

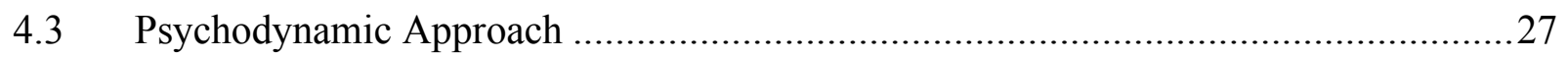

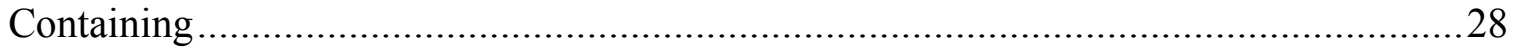

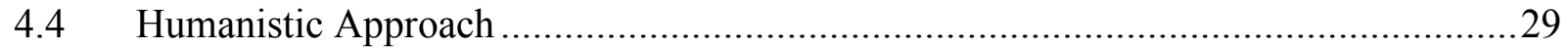

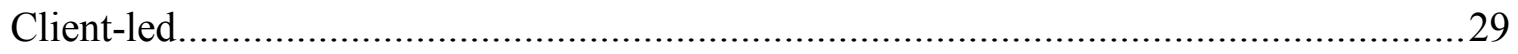

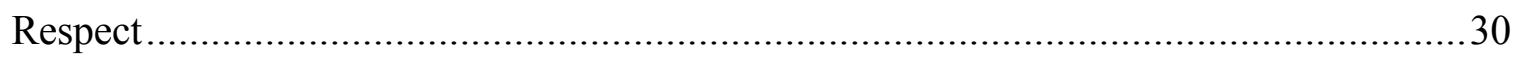

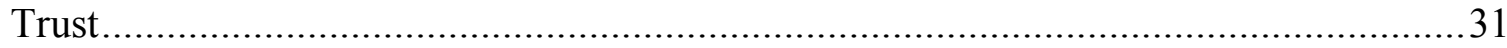

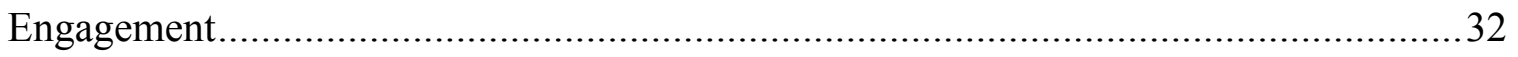

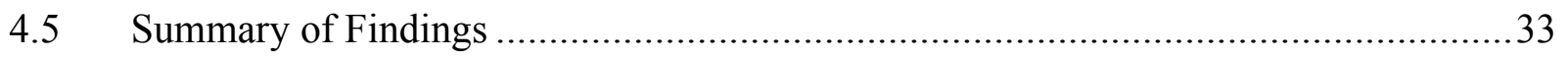

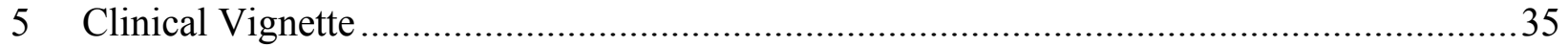

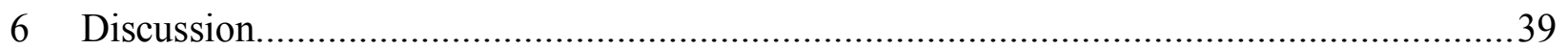

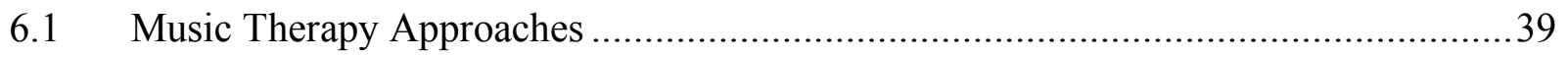

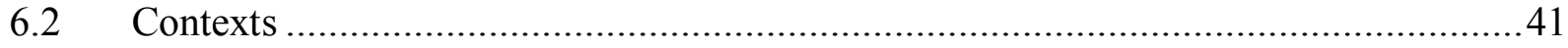

6.3 Relationships between Approaches and Contexts............................................42

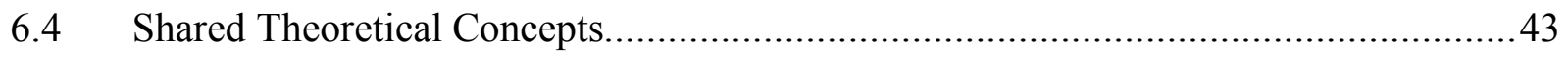

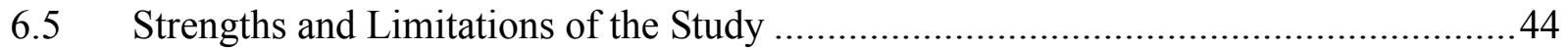

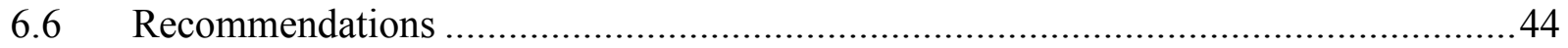

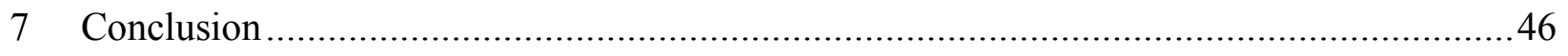

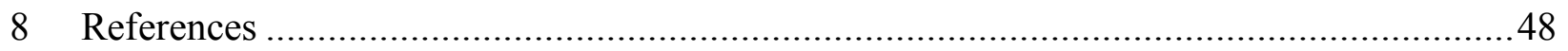

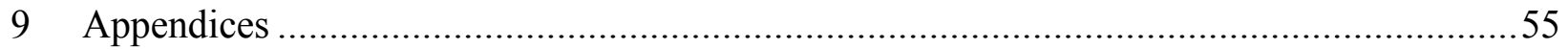

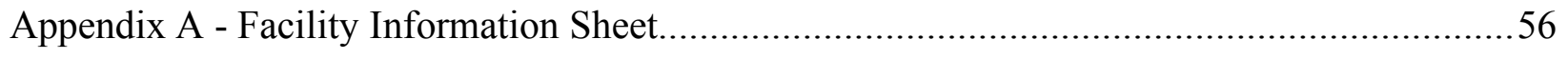

Appendix B - Client Information Sheet ....................................................................58

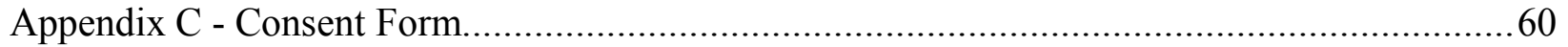

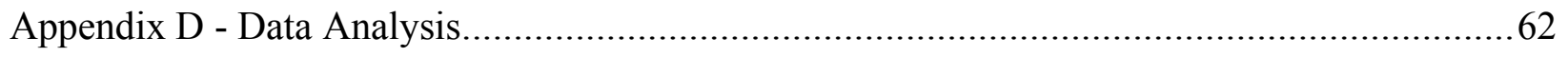

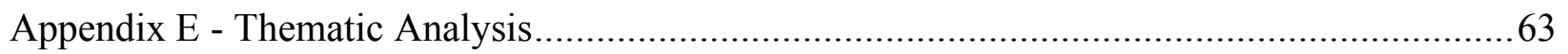

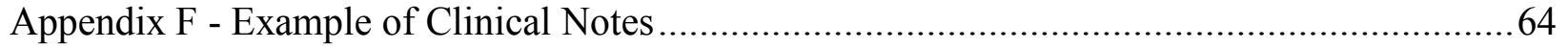

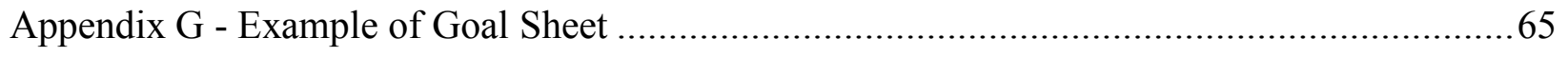




\section{Preface}

This qualitative research project explores my own practices as a student music therapist on placement at specialised facility attended by various client populations. Since this is a personal account of my work I have written in first person prose. It is important to acknowledge the stance of the researcher, as the nature of qualitative research involves the interaction between the researcher and the subject of inquiry. I felt it was essential to consider my personal experiences and background, and acknowledge the way they may impact my clinical work and research. As a student music therapist, I am still on the journey to discovering and understanding my own music therapy approaches. I believed that I was strongly influenced by humanistic perspectives when working with clients. This perhaps stemmed from music therapy training where my lecturers guided me towards a humanistic approach, my personal experiences, as well as my work experiences working with a variety of children as a caregiver. The clinic that I worked at employed music therapists from a variety of trainings, but I was mentored by a Nordoff Robbins trained therapist who also brought a humanist perspective to the work. However, it is also important to note that I worked with a variety of music therapists, who would have very likely had a strong influence on the way I chose to approach my practice. My learning was shaped and guided as a training therapist working amongst such a variety of experienced mentors. During my clinical placement, I also had the opportunity to work as a co-therapist with two experienced music therapists with contrasting orientations to their practice. On top of that, I was able to work individually with a variety of people; and I participated in weekly and monthly supervision. During my weekly supervision, I was able to explore my worries and questions regarding practice with a supervisor who shared much wisdom. I learnt that it was absolutely vital for me to utilise one-to-one supervision to the fullest extent. I feel that a lot of my growing, reflecting, and learning happened during my weekly and monthly supervisions. My research was guided by the constructivism philosophy, which is grounded by the principle that one's understanding is formed by reflection on their personal experiences and relating newfound knowledge to their existing body of knowledge; that mental structures and operations are actively constructed by one's mind (Riegler, 2012).

This introduction sets the research in context. It is followed by a comprehensive literature review highlighting relevant literature on music therapy approaches, including their theoretical tenets. In 
the methodology section I describe my data analysis process. Findings are illustrated with a clinical vignette in order to provide a case study example of the findings in practice. Finally, the discussion reflects on the findings and explores future implications of the research.

\subsection{Clinical Setting}

During my clinical placement, I worked at a facility, which provided music therapy services predominantly to young people with a wide range of special needs. There was also an outreach programme that involved satellite work at various schools and healthcare centers around Auckland. I practiced at one of the healthcare centers as part of the outreach service. The clients I worked with in the center were children and adolescents up to the age of 16, all with various intellectual and/or developmental disabilities such as autism spectrum disorder (ASD), and Down syndrome (DS). The clients in the healthcare facility are all young adults in their mid-20s with intellectual disabilities and/or various neurodevelopmental disorders.

\subsection{Research Question}

During the first months of my placement I noticed that different music therapists used very distinct approaches and methods in their practice, and I wondered whether this was likely to be influenced by the population they were working with and the contexts in which they were practicing. I aimed to investigate the significance of particular music therapy approaches to practice and to determine which of these approaches were most congruent with the ways my practice was developing. Because I was working with a wide range of populations, it was likely that I would draw on more than one fixed approach. That is, the diversity of practice demands diversity in approaches. My research question "what approaches did I draw on for particular aspects of my clinical work and why?" reflected the need to respond to this diversity in practice. 


\section{Literature Review}

This literature review explores in detail the different types of approaches commonly used in music therapy, highlighting their theoretical frameworks and perspectives, particularly the way in which we think about practice. Theoretical tenets and commonly held concepts of humanism, behaviourism, music-centered music therapy and psychodynamic music therapy are explored. Firstly, this literature review will cover the various influences that can impact and orientate the way we practice music therapy, briefly touching on gender, religion, personal philosophies and of course the various settings and client populations worked in. The types of music experiences in music therapy, i.e. compositional, improvisational, pre-composed, etc. are described, and the difference between music as therapy and music in therapy is explored, which is helpful in understanding therapeutic process in music therapy. There will be a description of the terms commonly used to describe the terminology used within music therapy, i.e. approaches, methods, models, techniques and strategies. For the purposes of this literature review, the term 'approach' will be used in a general sense, mostly pertaining to a conceptual framework, orientation and/or a music therapist's clinical thought. A range of literature was collected through online library databases including EBSCOhost, Google Scholar, JSTOR, SAGE Journals, ProQuest, as well as books and journals collected from the Victoria University library, public libraries and the library at the music therapy facility.

Keywords: music therapy approaches; music therapy models; music therapy methods; music therapy techniques; music-centered music therapy; person-centered therapy; humanistic; psychodynamic music therapy; client-centered music therapy.

\subsection{Influences on Music Therapy Practice}

The historical influences on music therapy have been hugely diverse, ranging from the influences from the development of therapy; music education; medicine, together with physiological, psychological and sociological bases (Hadley, 2003; Choi, 2008; Wigram et al., 2002). The diversity in music therapy clinical practice also reflected in context, i.e. among schools, clinics, hospitals, residential centers, nursing homes, hospices, prisons, community centers, mental health institutes, and private practices. Naturally, the goals or expectations of therapy will greatly 
vary from one setting to the next, together with the way in which the therapeutic relationship between the client and therapist is cultivated (Bruscia, 1998). A study by Choi (2008) conducted with 500 music therapists' affirmed that the therapists' areas of practice significantly influenced their primary approaches. Furthermore, his study addressed the somewhat controversial question of whether or not music therapists' can be eclectic in approaches (p. 108). Some schools or facilities may provide training that involves learning a variety of therapeutic theories to give flexibility and freedom within a diverse client population (Wigram, 2002). It is important to have a body of knowledge and skills congruent with the client population that the therapist is working with, as a diverse clientele will demand diversity in approaches. McFerran (2003) gives an example: "adolescents who are grappling with complex and existential issues do not...require the assistance or facilitation provided for those dealing with implications of intellectual or multiple disabilities" (p.2). There is a growing trend towards eclecticism in music therapy practice, further positing that no single theory is able to address the many layers of complexities of human behaviours, thus by adopting an integrative perspective, therapists can accommodate a wider range of needs and goals for each individual client (Baruth \& Huber, 1985). McFerran (2010) explains that the stance of the therapist is influenced by their practice based on the contexts they are prescribed, as well as the cultural and locational settings. Her data, collected from 140 music therapists working with adolescents, showed that 52 music therapists used a psychodynamic approach in their practice, while 23 out of the 52 music therapists also blended their practice with another model. The study showed that forty-four out of the 140 music therapists identified as having a humanistic influence in their practice, while 26 out of the 44 music therapists also blended their practice with another model. It also showed that twelve music therapists identified strongly with a behavioural model, of which 4 blended with other models. The remainder 32 identified as 'unknown/unclear' in their dominant theoretical orientation. A total of 53 out of 140 music therapists, or one third, chose to blend their practice with other models.

Grocke \& Wigram (2007) mention that regardless of age, context and the method of music therapy adapted - whether it be improvisation, songwriting or receptive techniques - our personal beliefs and philosophies will orient us towards the way we form a therapeutic relationship with all clients. Thus, it is important to have awareness of the possible factors that may influence our attitude to clients (p. 20). It is stated in the New Zealand music therapy code of ethics that a 
music therapist shall not discriminate against clients by race or culture, age, gender, sexual orientation, religious beliefs, socioeconomic status and political orientation (MTNZ, 2012). This is something that is widely recognised and understood among many practices. Constant reflection is necessary to prevent any triggers that may inhibit the therapeutic relationship between the client and therapist. Age plays a contributing factor where both the therapist and client are of similar age may develop a closeness akin to a friendship, while a relationship between a therapist and a much older client may develop a child-parent dynamic. These age dynamics influence the quality of the therapeutic relationship (Nelson-Jones, 2003). Religion or philosophy is a major contributing factor that can cause disagreements and even heated conflict among people, and can become an issue for people working with adult client groups. Grocke \& Wigram states that the therapist's role is to remain objective, not to allow his or her own personal beliefs to intervene. Furthermore, Grocke \& Wigram provide a clear example where personal beliefs about religion or philosophy may intervene in a therapeutic relationship - a client 'speaking in tongues' during a session might indicate a deeply spiritual experience, but to another it might be seen as verging on psychotic behaviour. A therapist who believes in the 'speaking of tongues' due to their religious orientation may then choose to affirm the client's spiritual experience, allowing a richer experience. The therapist who may consider it abnormal behaviour may inquire into the client's mental state of mind. There is nothing inherently wrong with either approach, albeit they are qualitatively and philosophically different, which demonstrates the diversity in therapeutic context and decisions that are influenced by personal beliefs and values (Grocke \& Wigram, 2007; Nelson-Jones, 2003; Rogers, 1995). It is possible that each therapist could hold a strong bias that their approach was correct due to their personal beliefs. It is important that the therapist seek professional supervision to address the issues being raised. On the whole, a wide variety of contextual influences can contribute to the way we approach music therapy practice, thus it is important to have awareness of our own beliefs and the contexts that might impact our practice.

\subsection{Defining Musical Experiences}

Models of music therapy are often broad and equivocal, meaning music therapists will not generally follow one approach strictly without employing elements from different philosophies

in order to address client needs. Music experiences are important to mention, as music therapy is 
the use of music experiences rather than just music itself. The 'experience' in music is defined as part of the client's experience of the music, i.e. the interaction between person, process, product, and context (Bruscia, 1998, p. 109). Bruscia (1998) states that there are four distinct types of musical experiences: improvising, re-creating/performing, composing and listening. These four types of experiences can otherwise be defined as methods, and as Bruscia mentions, any one method can have many variations, as there are different ways in designing these four experiences. Bruscia categorises music making in the following way: extemporaneous musicmaking falls under 'improvisational' methods; reproducing music with the client is 're-creative' method; engagement through composition with the client is a 'compositional' method; and lastly, engaging in listening experiences with the client is a 'receptive' method. The amount of procedures, strategies and techniques used within the four methods of music therapy can vary considerably, depending on the needs of the participants.

The terms model, method, approach, procedure and technique are frequently used interchangeably in literature, which can lead to some confusion in discernment of the terms. Bruscia summarises the terms as follows: "a method is a particular type of music experience that the client engages in for therapeutic purposes; a variation is the particular way in which that music experience is designed; a procedure is everything that the therapist has to do to engage the client in that experience; a technique is one step within any procedure that a therapist uses to shape the client's immediate experience; and a model is a systematic and unique approach to method, procedure and technique based on certain principles" (Bruscia 1998, p. 115). Davis et al. (2008) define a method as an organised and clearly prescribed way of teaching a particular skill, or a system for conducting therapy. In addition, they describe an approach as being a way of facilitating a session or teaching a musical skill (such as playing the keyboard). So, we can see that many of these terms can overlap and be used interchangeably in different contexts, for example, a therapist might use a Nordoff-Robbins model, which utilises the method of improvisation and has the theoretical tenet that embodies humanistic psychology (Robbins, 1993). One may also consider using these particular terms in somewhat different ways. Davis et al. (2008) provides an example where a music therapist might consider the Nordoff-Robbins as a model, while another might consider it more of a method. To reiterate, in this study the term approach will mainly be used to define a way of thinking or conceptual framework in music 
therapy practice. So, in a clinical context, one may go about employing various approaches at different moments in their practice, rather than be limited to one single approach.

\subsection{Music as therapy vs. music in therapy}

Paul Nordoff and Clive Robbins, who were the pioneers of music therapy coined the term music as therapy, as it predominantly manifested in the work they created, focusing on the art of music as the core of therapy (Nordoff \& Robbins, 1965, p.15). The term music as therapy stressed the philosophical foundation that the therapy is in the music. Bruscia (1987) explains the two different ways music is used during therapy: when music is used as therapy, music serves as the primary vehicle for therapeutic changes in the client. The therapist emphasises moments where the client relates directly to the music, with the therapist supporting the process or relationship when necessary. When music is used in therapy, it is no longer the primary vehicle but is rather used to facilitate the therapeutic changes through an already established interpersonal relationship (Bruscia, 1987). A particular model or approach can utilise both music in therapy and as therapy, although each model or approach might emphasise one of the clinical orientations over the other. A music-centered approach is considered an approach that focuses primarily on music as the core of therapy, thus being music as therapy (Aigen, 1999). Which clinical orientation one chooses to emphasise over the other will be reflected by the client needs in terms of their difficulties in nonmusical areas as well as the ability of musical experience to be self-contained without verbal facilitation, i.e., the musical experience can facilitate therapeutic growth for a client without the need to verbally work through a personal relationship with the therapist (Bruscia, 1998b).

\subsection{Approaches and Perspectives in Music Therapy Practice}

There are many things that influence the way in which we think and approach our practice. We can focus on the client population served, the goals addressed, or in this case, focusing on the approaches used by the therapist. It is also important to understand the multifaceted domains, such as clinical setting, diagnosis, age, and theoretical orientations of the therapist, all converge into a guiding framework that helps us understand the complexities of clinical practice (Meadows, 2011). As models of music therapy are often broadly and loosely defined, it is not 
uncommon for a music therapist to adopt more than one approach, employing elements of different philosophies in order to address client needs. Not all music therapists will have a clear philosophical orientation towards their practice; music therapists are generally eclectic in their practice to accommodate for the wide range of client population in various settings (Choi, 2008). A study done by Silverman (2007) revealed that when music therapists had to identify their philosophical orientation with one single choice, $39.3 \%$ of music therapists identified their practice as being eclectic, whereas $37.6 \%$ identified as behavioural, $14.2 \%$ identifying as humanistic, and the remainder responding with psychodynamic, cognitive, and biomedical orientations. However, Silverman's study was conducted in a particular cultural context, that is, the USA. It is worthy to note that this may not be indicative of what happens in other countries.

It is important to mention an approach is not merely defined by a specific therapeutic action, but rather the therapist's understanding or clinical thought, that is, acknowledging the therapeutic process and conceptual framework. In this case, it is more the frameworks of thinking that defines our approaches. For example, psychodynamic music therapists can employ a variety of music therapy methods from realms outside of psychotherapy, such as vocal improvisation, songwriting, and music imagery (Austin, 1999; Darrow, 2008). Furthermore, a music therapist can be psychodynamically oriented but not psychodynamically trained, that is, the music therapist believes that working through transference is central to therapeutic change (Wheeler, 2015). Within music therapy, there can be a variety of orientations and approaches that underpin a particular method or model. Aigen (2014) suggests that orientations are merely an invocation or 'tendencies of thought' and should not be thought strictly as 'models' as they do not include 'specific interventions, procedures and goals' (p. 223). Bruscia (2011) concurs that orientations can simply be a 'way of thinking' rather than following a strict set of theoretical frameworks. These different and unique ways of thinking means that the focus of enquiry differs for each music therapist and should always be looked at on a case-by-case basis (Pavlicevic, 1997, p. 6). For example, practice could be behaviourally informed without being a behavioural approach. Also, through the clinical vocabulary or language, we are able to define the commonly held concepts that underpin the various approaches in music therapy. The classifications of approaches vary greatly among literature but will be simplified under psychodynamic, humanistic, behavioural, and music-centered approaches in this literature review (Choi, 2008; 
Thaut 1999; Wheeler, 2015; Darrow, 2008; Davis et al., 2008; Scovel \& Gardstrom, 2012; Baker, 2015; Bruscia 1987/1997/1998; Meadows, 2011; Rogers, 1951/1999; Aigen, 2005).

\subsection{Music-centered Approaches in Music Therapy}

The term music-centered is potentially applicable to theory, clinical practice and research. That being said, the more one's practice emphasises music-centered thinking, the more likely that the use of music is used as therapy rather than music used in therapy; it is not to say that music must be the primary medium in response to the client, but that the music therapist emphasises musical expression and experience, acting on rather than acting through (Aigen, 1991a; Bruscia 2002). Although, the goal of music-centered work is the "achievement of experiences and expression specific and unique to music, the clinical and the musical aspects are not separable. What is achieved through the music cannot be approached in any other way because musical experience and expression are the goals of therapy" (Aigen, 2005, p. 56). Musicing is the premise of musiccentered practice; the primary focus of a music-centered approach is to bring the client into a state of musicing, verb coined by Small (1998) that essentially means 'to music'. Elliot (1995) defines the term musicing as a "particular form of intentional action... as to act is not merely to move or exhibit behavior. To act is to move deliberately, with control, to achieve intended ends... [thus], to perform music is to act thoughtfully and knowingly" (p. 50). Music-centered approaches seek to uncover and explain these musical experiences and phenomena, as musiccentered approaches have the flexibility in focusing on the specific musical structures and processes that unfold during a music therapy session, i.e. the tonal, rhythmic, harmonic, and stylistic components of clinical music (Aigen, 1995a). Musicing embodies the importance of respecting and understanding silence, as silence in music-centered therapy is seen as a place of patience, receptivity, and of waiting (Langdon, 1995). Being able to understand, grasp and embrace silence is very central to the music-centered perspective; being able to connect with silence also means being able to connect with the client on a deeper level. In music-centered practice, allowing the room to fill with silence can be very intimidating, but looking from an inversed perspective it can actually facilitate the deepening of atmosphere in the room. Furthermore, musicing requires listening intently to our clients in regards to the intricacies in the music. Music-centered thinking recognises that aesthetic experience is an essential psychological human need; it recognises that the aesthetic quality of music in music therapy is not incidental to 
clinical processes but is essential to these processes. Aesthetic properties can be: complexity, simplicity, beauty, novelty, unity, rhythmic cohesion, strength of representation, expressiveness (Aigen, 2005).

\subsection{Behavioural Approaches in Music Therapy}

The purpose of behaviourism is to offer more adaptive learning experiences and behaviours, while undoing dysfunctional learning and thought patterns. A behavioural approach in music therapy means focusing on adaptive learning experiences and behaviours, whilst mitigating dysfunctional learning and thought patterns; it is about behaviour modification, active participation, constantly evolving formulations, attention on the present, and is usually goal- or problem- oriented focused (Hanser \& Mandel, 2010). Behavioural music therapy requires a solid understanding of the principles of behaviour and also the ability to design sessions and procedures accordingly. A fairly recent survey conducted on music therapists in psychiatric settings revealed that behavioural approaches were used by $83.1 \%$ of the respondents (Silverman, 2007). In behavioural music therapy, music can be used as a cue, as a time and body movement structure, to redirect focus of attention, and as reward. One of the commonly held concepts in behavioural music therapy is that the object of behaviourism is to be able to observe, identify, analyse and modify behaviour. The behavioural approach recognises that cognition and affect can be quantified through observable means (Madsen, 1999). Once a particular behaviour is identified, the therapist then works towards modifying this behaviour by introducing contingencies into the environment to influence the client's behaviour in a positive direction. This is not to say that behaviourism focuses on dependence of contingencies and rewards. Behavioural music therapy hopes to allow clients to reach a point of independence and intrinsic enlightenment but is worked towards within these behavioural principles and operant techniques. Some common techniques in behavioural music therapy include: prompting, which is when a therapist provides a directive in which the client will emit a desired response; positive reinforcement is when that desired response is emphasised and rewarded with a contingent presentation by the therapist, to increase the probability of the desired response (Madsen $\&$ Madsen, 1998; Alberto \& Troutman, 1995). 


\subsection{Psychodynamic Approaches in Music Therapy}

Psychodynamic music therapy can be defined as a music therapy approach that is informed by psychodynamic theory, which originates from Freudian theory concerning the ego psychology, object relations theory, and self-psychology (Isenberg, 1998). Silverman (2007) conducted a study with music therapists working in a psychiatric setting and found that $49.2 \%$ of the music therapists used a psychodynamic approach, but only 5.7\% listed psychodynamic theory as their primary philosophical orientation. This reveals the complexities of psychodynamic music therapy as there are many models of psychodynamic theory, each having different theoretical and clinical emphases. As psychodynamic therapies are derived from psychoanalysis or the "talking cure', does that mean the use of music as a nonverbal modality is incompatible with the verbally based psychodynamic theories? Whether music therapy should rely exclusively on theories within the realm of music therapy has not been clearly resolved (Isenberg, Goldberg, \& Dvorkin, 2008), but Wheeler (1981) and Ruud (1980) both suggest that relying on psychotherapeutic theories have the advantage of providing a conceptual map for clinical work.

Isenberg (1998) outlines some of the core principles that psychodynamically-oriented music therapy strives to attain, and this is that the music therapist: addresses questions of meaning; acknowledges that past experiences can impact the present; acknowledges the unconscious having influence over behaviours, thoughts, and feelings for both the therapist and client; recognises and believes in the centrality of transference and countertransference within a therapeutic context and utilises the experience to build an greater understanding of the client to work through change; lastly, that the music therapist has a solid understanding of psychodynamic theory and its conceptual framework. A psychodynamic approach embodies the concept that the client is able to 'discover' him or herself (Wigram et al., 2002). Winnicott (1971) adds that both the therapist and the client have to be able to 'play' before any sort of 'psychotherapy' can begin, as it is only in playing that the client is able to be create and tap into the whole personality and discover the self (p. 63). Bruscia (1998) notes that using a psychodynamic approach means engaging the client with music experiences that will evoke feelings and interpersonal dynamics that are problematic, and at the same time, reshaping or resolving through the music (Bruscia, 1998). Alexander Stein (1999) describes music in respects to psychoanalysis as "a primary

process experience, which defies absolute comprehension or satisfactory secondary 
elaboration... By naming the feeling felt while listening to music through a process of analogy and symbolization, we effectively translate the feeling into something else (p.401). It is the process of bringing unconscious material into consciousness through musical experiences within a therapeutic relationship. Psychodynamic therapy is constituted by the culmination in transference (Choi, 2008). The transference can be projected onto the therapist or it can be between the client and instrument in music therapy. Psychodynamic music therapy employs the idea that music can provide a psychic container and also facilitate the expression of unconscious fantasies in a safe therapeutic environment (Noy, 1966; Lecourt, 2004). Particular psychodynamically informed methods are: Analytic Music Therapy (AMT), Psychodynamic Therapy, Interpersonal Therapy, Guided Imagery (GIM), Behaviour Therapy and Cognitive Therapy (Corsini \& Wedding, 2005). A common technique used within a psychodynamic approach are the holding or containing techniques, where the therapist facilitates a psychic container, holding the client musically to promote full freedom of emotional expression. Although containment and holding are similar, there are fundamental differences between the two. Bion (1962) gives an example of containing as feelings projected to another that are fearsome, painful or in some way, intolerable. In return, the feelings that are projected are felt by the recipient who is not able to react to it, and instead deals with the feelings by containing it and then returning it to the sender, so that they can 'repossess it and reintegrate the emotion as their own' (Bion, 1962). Holding is the concept of the 'holding environment' based on a mother/infant bond. Winnicott (1971) describes the 'holding environment' as an optimal environment for 'good enough' parenting. They both involve the therapist striving to offer an emotionally protective, enabling space which metaphorically holds the client and contains their emergent feelings (Finlay, 2015).

\subsection{Humanistic Approaches in Music Therapy}

A humanistic approach in music therapy is largely informed by the theoretical tenets of humanistic psychology. Humanism is based on the belief that each client, regardless of disability, is self-governing of his or her autonomy. The humanistic approach is governed by a holistic and person-centered approach that focuses on innate creativity, personal freedom of self-expression 
and growth within the client (Bunt \& Hoskyns, 2002; Wheeler, 2015). This person-centered approach ultimately focuses on the importance of the client-therapist relationship and the notion of 'wholeness' (Bunt, 1994; Corey, 2009; Rogers, 1999). The core construct of humanism is selfactualization of one's potential. The underlying principles of a humanistic psychology are congruence (transparency and genuineness), unconditional positive regard, and empathetic understanding towards the client. Weissmann (2008) states that the humanistic approach emphasises compassion, kindness, and respect for others. The humanistic approach is a useful approach for clients with mental illnesses, as people living with mental illness continue to encounter challenges and to be treated with less than full measures of trust and respect (ShallyJansen, 2013). In a humanistic approach, the therapist demonstrates unconditional positive regard through warm acceptance that encourages clients to grow within the therapeutic process (Smither, 2009). Open-mindedness and a keen desire in exploring human behaviour are quality traits that can help facilitate client change (Rogers, 1995). Humanistic therapists strive to help their clients achieve a greater degree of independence and integration by focusing on the person him/herself and not the person's issues (Corey, 2009; Unkefer \& Thaut, 2002). For example, facilitating engagement for a client with a community music performance can contribute to a client's possibilities for increased self-esteem, while also challenging the client's capacity to accept responsibility for the quality of the public aesthetic product (Scovel \& Gardstrom, 2005). In humanistic approaches to music therapy, individuals are regarded in a uniquely human context, as beings superseding all biological or psychological 'barriers'. It is important that also trust in the actions of the client. The trust in the humanistic approach means believing that clients are able to demonstrate potential for self-determination and their journey to actualization (Maslow, 1968; Bunt, 1994). Humanistic perspectives in music therapy are more focused on the existential aspect rather than the objective and tangible aspect of things (Abrams, 2014; Wheeler, 2015). Determinism is a key concept within humanistic psychology - that 'man is ultimately selfdetermining'. Humanism means that human beings supersede the sum of their parts and cannot be reduced to components; that human beings exist in a uniquely human context; that human beings are aware of being conscious, including in the context of others; that human beings have the right to choice and responsibility; and lastly, that human beings possess autonomy, thus are intentional, have goals and also seek meaning, value, and creativity in life (Bugental, 1964; Frankl, 1967; Leonard, 1987). While humanistic music therapy draws from the core principles of 
humanistic psychology, humanistic music therapists have their own unique character and set of principles within their practice. The core components of humanism in music therapy are the clients, the music, therapy goals, and therapy processes. Each of these components are subject to the core constructs of humanism, which are: being, holism, agency, and relationship. In a humanistic approach, it is not to say that one does not focus on the music. It is just that the clinical thought towards improvisation or musical interaction is based on the commonly held concepts of humanism, which is in a music therapy context, the client-therapist relationship and empowering the client. The humanistic approach is to treat body, mind, soul, and emotions as all being intrinsically tied together as an indivisible whole. Any technique can be from a humanistic perspective, provided that it ultimately serves a humanistic purpose (Bunt \& Stige, 2014; Scovel, \& Gardstrom, 2005; Wigram, Pederson, \& Bonde, 2002)

\subsection{Summary}

When determining which approaches are most suitable, one has to make sure that all of the client needs are addressed. Bruscia (1993) asserts that "when creating a definition, it is important to consider which facet of music therapy or which clinical approach will be of greatest interest and relevance to the person inquiring" (p. 1). Therefore, it is the therapist that defines their approach to music therapy, and how the music will be represented in the therapeutic practice with the client. The profession of music therapy must continually apply, critically regard and develop from existing theories in psychology, psychoanalysis, education, musicology, medicine and communication (Wigram et al., 2002, p.71).

\section{Methods and Methodology}

\subsection{Theoretical Framework}

This research study was informed by a constructivist epistemology. Crotty (1998) describes constructivism as the notion that meaning is constructed, rather than discovered; and that 'different people construct meaning in different ways, even in relation to the same phenomenon (p. 9). Each person's unique experiences and mental representations play pivotal roles in interpreting physical reality as well as moral and social understanding. It is the language that constructs and defines our subjective experiences. Qualitative research in music therapy strives to understand and interpret our own practice as well as the complex responses from our clients 
(Kirkland, 2013). In a constructivist paradigm, all inquiry is subjective and value-bound. Constructivist researchers seek to understand the contextual meaning created by both the client and therapist during music therapy practice. As a student music therapist with diversity in musical background and training, I recognise that I am largely influenced by a humanistic philosophy. Furthermore, it is important to acknowledge all the contextual influences that have impacted this study during my data collection and placement period.

This research project utilised the methodology of Secondary Analysis of Data. Secondary analysis of data is a methodology for doing research that uses pre-existing data as a primary data source. The data is used to answer a question that was not initially intended by those who collected the data. The data that is already collected is being put into a new context and analyzed with the meaningful purpose of answering the research question. Secondary Analysis is the reuse of data for the purpose of attaining clarity in answering the proposed research question (Heaton, 2004). Secondary analysis utilise the researcher's own collected data, or data from another study (Herron, 1989). This means data such as clinical or self-reflective notes, video or audio recordings of sessions that have been collected as part of my clinical record keeping, were reused as a data source to answer my research question. My clinical data and reflective notes were subject to thematic analysis, involving both inductive and deductive thematic analysis of data. Thematic analysis of data is the process of coding, sorting, and organizing data, in order to draw themes within the data. This method of inquiry is useful for this study as thematic analysis allows for flexibility and for rich, detailed and complex description of data (Braun \& Clarke, 2006). I used thematic analysis to examine my clinical data in order to find out which approaches I drew on when working with a wide range of clients in various settings.

During my music therapy placement, I routinely wrote clinical notes, and reflected on the work, after every session, to record client progress, support planning, and improve my practice. Data sources included clinical notes (a descriptive summary of the music therapy sessions), selfreflective journal (my personal feelings and thoughts about the session in more detail, including awareness of myself and my music therapy approach), audio and video recordings. Permission was requested from the facility for the clinical data to be used in my research, and individuals were asked for their permission for their data to be included in the study. 
Secondary analysis can be a form of naturalistic inquiry where the collection of data is done in a way that has minimal impact on the intervention (Given, 2008). In this study, review of clinical data and journal notes was only done after music therapy sessions had ended with the clients. 


\subsection{Data Analysis Process}

I am familiar, through my training, with humanistic, behavioural, music-centered, and psychodynamic approaches to music therapy. I assumed that these would be the approaches that I would mostly use in my work. The first thing I did was to find out from the literature the various parameters of the main music therapy approaches - or at least the ones I am most familiar with and/or trained in. As the placement facility adopted a very eclectic approach in their practice, I was able to be very flexible in my practice, often drawing on elements of various approaches (see Appendix D - Data Analysis \& Appendix E - Thematic Analysis).

Firstly, I selected data that described what I was doing in the session (column C). I then questioned what I was doing in terms of approach (column D), and gave that a code (column E). If there were two or more approaches that emerged from one session, I would code the summary twice with differentiating the data with column $\mathrm{E}$ which coded each summary with an approach. I examined my summary a second time to uncover the primary reason for initial coding, i.e. what technique was I using that made me think this was part of a particular approach? For example, where Code 1 was 'psychodynamic', Code 2 could be 'holding' or 'containing' which is a concept most strongly associated with a psychodynamic approach. I then went back to the literature to find confirmation that I had coded my practice appropriately (column F). I went through this process with each of my clients and then cross-coded the data between the all my clients to find any patterns that emerged among them (see Appendix E - Thematic Analysis). 


\subsection{Ethical Considerations}

During my placement as a student music therapist, my clinical practice was guided by the Code of Ethics for the practice of Music Therapy in New Zealand (2012), the professional code of Human Ethics Policy under Victoria University of Wellington (2017), as well as conforming to the University's Treaty of Waitangi Statute (2009). This research project was given approval under a generic template for the Master of Music Therapy course NZSM 526 Casework and Research on the 04/04/2017 by the Victoria University of Wellington Human Ethics Committee (Ethics Approval: 22131). As this study involved a vignette of clinical practice, the guardian/caregiver of the participant was sent a client information sheet outlining the details of the research study and also a consent form, which was approved by the guardian/caregiver of the participant. Informed consent was also approved by the facility for the use of clinical data. To protect the anonymity of participants, pseudonyms were used, although it is possible that some key people associated with my work may be identifiable. The overall nature of my research project was low risk, since it relied on secondary analysis of data and did not involve any change to typical music therapy practice. However, as all the clinical data and journal notes involved other participants, and I had been working with a potentially 'vulnerable' population, precautions and ethical mindfulness were exercised throughout this research project to ensure the safety of all individuals. My clinical supervisor, co-therapists and the staff at the facility helped me navigate through very delicate territories comfortably and naturally. 


\section{$4 \quad$ Findings}

The approaches I drew on were Humanistic, Behavioural, Music-centered and Psychodynamic, as elaborated on in the literature review. My findings, below, demonstrate how I used the parameters of each of these approaches in my work and why. My findings demonstrated which techniques, actions or clinical thought process I had during any given approach in a session, for example, I used mirroring to engage with a client within a music-centered approach, i.e. focusing on the aesthetic dimensions of the music. While the focus on the relationship is still important, my ways of thinking stemmed from how I could alter the aesthetic dimensions of the music to facilitate a strong client-therapist relationship and a powerful musical experience. The findings also show the influence of working with a co-therapist.

\subsection{Music-centered Approach}

Supervision meetings with my co-therapists greatly influenced the way I thought about musiccentered practice. Through indexing (viewing video of practice and marking key moments) with my co-therapists, I was able to see how music could be used as the core of the therapy to support the client's growth and development. Music-centered approaches often manifested in my cotherapy sessions, where the co-therapist and I would alternate roles between the leading therapist and the supporting therapist. I often employed a music-centered approach when working with clients with autism spectrum disorder (ASD), using the music-centered approach to engage in meaningful musical interactions or musicing. My findings suggest that a music-centered approach was motivated by exploring different domains within a platform of improvisation. It was through improvisation, where 'matching' had emerged in every music-centered approach, while 'creating' was the only theme that appeared in a music-centered approach but did not emerge in any other approach. It is important to note that the momentum of the improvisations also depended on the input of the co-therapist, who was also primarily influenced by a musiccentered framework. It also helped that I was able to discuss challenges and strengths about each session during my weekly supervision with the co-therapist. 


\section{Mirroring}

In music therapy, mirroring occurs when the therapist echoes back what the client has produced, i.e. any form of sound or rhythm. Wigram (2004) describes mirroring as being able to imitate the form, rhythm, or melody in what the client does. Mirroring is usually done in the form of improvisation, where the therapist mirrors the patient's musical expression. Mirroring helps the client become aware of new parts of the personality as they emerge as sounds. It could be repeating words or melodies back to the client (Cohen, 2017). In my work I was often mirroring my clients' movements, gestures and/or instrument play. For example, when the client banged on the windows, I would mirror the client by strumming a chord on the guitar in the same rhythmic way the client banged on the windows. These mirroring moments would usually lead to a calland-response interaction. I often used mirroring because I wanted to engage with the client, and this strategy helped to initiate interaction. When mirroring, I often focused on the musical qualities of our interactions, thus mirroring was used within a music-centered approach.

'Seto walked over to the window and began banging on the windows in the form of quick triplets. I allowed this and proceeded to mirror him on the guitar with three downward strums in quick succession... He looked over at me with a big grin across his face.' (Seto's Clinical Notes, Session 10 - 01/04/17)

The mirroring usually reflected the client's rhythmic playing and was used to create a beginning of a musical experience. For example, when a client would begin tapping on an instrument, I would begin mirroring and gradually build up in rhythmic and dynamic intensity. The client would sometimes respond by beating louder on the drum and I would then develop an improvisation through the grounded rhythm that has been created from the both of us. This would also help facilitate a strong client-therapist connection through music making.

\section{Matching (Musically)}

In music therapy, matching is an improvisational strategy, often used as a starting point to work together with the client musically. The therapist produces music in response to the client to validate their playing and emotional expression (Wigram, 2004). Wigram (1999a) defines matching as improvising music that is compatible, matches or fits in with the client's style of playing while maintaining the same tempo, dynamic, texture, quality and complexity of other musical elements. In my work I was often matching clients musically. I would match the 
atmosphere of the room, or try to match the responses of the client, i.e. smiling, frowning, laughing or jumping around the room. For example, I used slow, steady and ballad-like music to match the client's drowsiness, often using broken chords too. Hugo was an 18-year-old boy with ASD. Hugo liked freedom in his sessions, so I facilitated this by not imposing a strict session structure. Instead, I allowed Hugo to explore freely within the room, placing a variety of instruments around the room, in which he would spontaneously go and play from time to time. He was often very tentative with his playing, as if he were musically dipping his toes in a pool to check the temperature. I would tiptoe around him, often strumming broken chords and letting them ring and slowly fade away. This clinical excerpt demonstrates the use of matching, which ultimately culminated in a form of engagement, creating, and also building a connection through music making.

'Hugo began rummaging through the instruments, not paying attention to any instrument in particular. I began matching him with the guitar, lightly strumming some major chords, allowing them to ring and fade away. I allowed him plenty of silence in between the chords, as there was a degree of uncertainty but I did not want to impose musical structure just yet... At one point I moved over to the piano and started playing a rocking pendulum rhythm in a major key with a sprinkle of dissonances, supporting Hugo's 'inspection' of instruments as he increased in consistency... I had tried to convey a combination of a sense of mystery and playfulness. Hugo had responded with some playing on the glockenspiel, although in a rather amorphous manner... Later Hugo had independently moved towards the keyboard that was placed near the middle of the room, far away from the cluster of instruments near the window where he sat. He had crawled over and started playing near the low register of the keyboard, mashing the keys in a repetitive set of quavers, something along the lines of 8 8月. Hugo stayed at the keyboard for a sustained amount of time $<5$ minutes, playing with the pitch bender while allowing me to join him on the keyboard' (Hugo's Clinical Notes, Session \#13 - 22/05/17)

\section{Creating}

In a music-centered approach, the therapist attempts to create a musical atmosphere for the client, establishing a musical experiential world for the client to live in. Music is used as a communicative medium. "Intentional action, emotional self-expression, human relationships are all aspects of our day-to-day lives that can be closed to others. Yet, through establishing a unique musical world for each client, experiences of these necessary qualities of human life can 
be imparted to them. It is as if music can establish an intermediate plan of existence in between the normal social world of human beings and the extremely isolated and individualised worlds of disabled individuals" (Aigen, 2005, p. 147). In a way, I saw creating as a means of providing musical support for my clients. In my work, I often created a musical atmosphere based on the responses and moods I picked up from the client, using my therapeutic intuition to create a wellsuited musical atmosphere. For example, when a client looked rather drowsy, tired or 'sad', I would base my musical momentum from that and begin playing a broken chord melancholic melody on guitar and hum very softly. I would continue to expand and build on the atmosphere with any further responses from the client. I often provided musical support during co-therapy sessions, where there would be two alternating roles between us - that is, the leading therapist and the supporting therapist. In my co-therapy sessions, I provided musical accompaniment to the leading therapist who would usually be improvising on the guitar. The co-therapist generally gave me a plan for the upcoming session and helped me decide which techniques to utilise, e.g. when notified that a client had been having tantrums, it was generally advised by the co-therapist to approach tentatively, allow the client space and introduce improvisations at an appropriate pace. Astute observations of client responses were always crucial in navigating the momentum and direction of the music. I mostly used percussion instruments to contribute to the aesthetic qualities of the music. As the co-therapy sessions progressed, I began to take confidence in leading the session, often creating a musical atmosphere for my clients. I found myself gravitating towards the guitar mostly, as I felt that percussion instruments could not provide the rich harmonic containment helpful for the musical atmosphere. Using the guitar helped me easily convey tempo, harmony, rhythm and timbre, while still allowing my voice and facial expressions to further contribute to the musical atmosphere. Furthermore, my music therapy training and my knowledge in jazz progressions would have also contributed to my improvisation styles. It is important to note that the co-therapist had also greatly contributed to the direction of where the improvisation would go and many times, the co-therapist would lead the improvisation from scratch and I would join in with the client as seemed appropriate.

'Dwight had walked in and made himself comfortable on the beanbag near the far windows. He seemed to be quite comfortable exploring through the basket of instruments with [the co-therapist], who sat near him and also explored the instruments with him. I began some improvisations on guitar in a major key, 
reflecting Dwight's seemingly content and joyous mood as characterised by him lying down on the beanbag and sifting through the instruments whilst lightly chuckling to himself. [The co-therapist] would match Dwight using various instruments from the basket, but he made sure not to impose structure to Dwight's tentative playing. At times, Dwight became interested in the sound and reached out to take the instrument from [the co-therapist] to play (the sticks, triangle, tambourine). I saw this as an opportunity to provide momentum in the music, altering the musical elements such as dynamics or timbre. I attempted to convey a sense of playful curiosity with my playing. Our improvisations transitioned into a progression of leaping back-and-forth $F$ and $G$ bass over an $F$ major power chord. The grungy dissonance in the progression conveyed a sense of uncertainty but was contained with an underlying drumbeat by [the co-therapist]. The music was mysterious but invited participation through the captivating and forward-thrusting rhythmic momentum, which Dwight seemed to really engage with... he began tapping his feet to the improvisation and spontaneously playing on the instruments he had in hand (triangle, tambourine, sticks). Often, sustaining entire phrases on the tambourine (Dwight's Clinical Notes, Session \#17 - 03/06/17)

\section{Engagement}

In the music-centered approach, the primary focus was to bring the client into a state of musicing which I also saw as a form of engagement with the client. Musical improvisation, clinical or otherwise, has a practical and shared interpersonal framework: themes are stated, repeated, developed, and "presented to make a coherent" whole (Aigen, 2005, p. 153). In my work, I would use a variety of methods in order to engage clients, these would include: improvising music, matching the client musically, using familiar songs, providing turn-taking opportunities, allowing space for client or freedom in structure, captivating rhythms, expanding musical atmosphere and direction, offering instruments to clients, or inviting clients to engage in musical activity. For example, when a client walked in a joyous manner, skipping and jumping, I would accompany his mood with exuberant and upbeat music, matching his movements. If the client responded positively, I would continue to build on this uplifting music and expand the themes, usually increasing with intensity, giving direction in the music. I would also expand on the responses from a client and develop it into a theme and then represent them in our improvisations. Being comfortable with silence in the room is something that I was able to cultivate, refine and use appropriately to invite participation from clients. Aigen (2005) adds that well-paced silences can evoke a client's musicality as much as can inspired musical 
interventions. I would also spontaneously improvise and also offer clients various instruments to play on, gently prompting but with no expectation as the core of the session was in the musicing together.

'Hugo picked up wooden shakers and began playing with them tentatively. I played back and forth progression of A-E with a rocking bass line. He noticed the music, engaged in eye contact and began to shake the instruments with increasing vivacity. Hugh was attentive to the music as he looked at me and smiled at me during our music making... I began playing through spontaneous jazz chords and Hugo became gradually more engaged as I got up and moved with the rhythm. As the improvisation rises to its climactic stages, Hugh's playing becomes more continuous. He would respond accurately to compliment my rhythms and I would affirm this by trying to make eye contact and verbally and physically give him praise by smiling. Hugo was more reserved, but the change was seen in his rhythmic entrainment when he engaged in the music. Hugo would say that he wanted to dance but he would need a good deal of prompting to stand up and actually dance. However, in this session, when Hugo remained seated in his chair, he would rock his body slightly back and forth to the music. Hugo was also able to vocalise when directed and also followed a 'call and response' procedure throughout. The session ended with a transition from a blues medley into our standard greeting song' (Hugo's Clinical Notes, Session \#5 - 13/03/17)

\subsection{Behavioural Approach}

Weekly supervision with my clinical educator influenced the way I thought about a behavioural approach as I often thought about balancing behavioural management and therapy in my sessions with some clients. Through reviewing clinical footage with my clinical educator, I was able to see where a behavioural approach could improve the structure of my sessions and work towards goals. Behavioural approaches would often manifest in my sessions with Dylan, where I frequently used behavioural techniques such as redirection, positive reinforcement, and modelling.

\section{Modeling}

In behavioural music therapy the music therapist will demonstrate an action that needs to be taught to the client (Darrow, 2008). In my work, I showed clients how to stomp their feet, spin around, dance, and so on; and I would show them how to engage in a body percussion activity. I 
also modeled how to play instruments correctly. For example, I demonstrated how the recorder, harmonica was played, and then I would hold the instrument out in front them, verbally prompting them to play. I used modeling with clients to facilitate new behaviours and introducing new activities, for example, when a new activity required a new instrument to be played in a structured manner, I would model this by playing this through once and then allowing the client to give it a try. Modeling was shown to be very effective for introducing new activities and was usually used to facilitate structure within an activity. Verbal modeling with positive reinforcement helped the client learn new actions in activities. Later on, I would gradually fade out modeling for a particular activity, and just use minimal to moderate prompting when needed. Modeling was important in my practice with clients that would often need continuing novel experiences in session to stay engaged in session. Furthermore, it also helped with clients who experienced communication barriers, i.e. speech difficulties or hearing loss. I was able to introduce new activities and demonstrate how to participate in an activity through the use of both verbal and nonverbal modeling.

'Introduced a song with a call-and-response section that encourage the use of vocalization. I demonstrated the 'la-la-la' call-and-response section and modeled this with facial expressions, i.e. cuing with eyes and facial expressions, etc. Later, I encouraged him to give it an attempt, and with moderate prompting, he was able to respond perfectly in time to the music. I positively reinforced this by affirming his actions with facial expressions' (Dorian's Clinical Notes, Session \#17 - 17/06/17)

Modeling also was useful for facilitating engagement at times. For example, when I introduced new instruments and began modeling them, the client would usually become interested and engage in instrument play with me.

\section{Structure (Activities)}

In behavioural music therapy, structure can encourage appropriate behaviour and increased vocalizations/participation/engagement. The therapist uses structured activities to allow the client to clearly understand what is expected of them. A structured session allows stabilization and builds security in the music room/placement. Music can be organised into games and structured activities to encourage respect for boundaries, reciprocal interaction and shared appreciation (Oldfield \& Flower, 2008, p. 171). In my work, I often used structure to give the client a sense of clear expectations. For example, each session had a fixed greeting song, but within greeting song 
had various sections, one of which the client was able to improvise freely. I used plenty of precomposed action songs that helped with structuring activities. These action songs would facilitate vocalisations or fine motor skills, such as holding a mallet or singing back a call-andresponse phrase within an activity. The predictability, repetitiveness and simplicity made the activities easy to participate in, thus I was able to expand and tailor activities to effectively address client needs. Each session also finished with a consistent closing song, to give the client a sense of structure and stability. A typical session was structured broadly with a greeting song, a variety of activities, a transition to closing, and then followed by the closing song. It is not to say that structure omits freedom and flexibility. Structuring the activity to allow spontaneity, freedom, and improvisations is also necessary to add momentum and excitement into sessions. Implementing freedom and flexibility within a structured activity allowed the client to explore within the boundaries of the activity, in which I was then able to explore the clients various strengths and challenges, allowing me to engage my client more effectively.

\section{Positive Reinforcement}

In a behavioural approach, the therapist uses positive reinforcement to increase or encourage specified target behaviour, while another targeted behaviour is being reduced or eliminated (Darrow, 2008, p. 115). Once established, the reinforcement is gently thinned until the newly established contingencies are no longer necessary. The therapist might use positive reinforcement when a client is actively engaged in an activity and demonstrating instrument play, for example, when the client responds to the therapist by playing on the drums, the therapist will positively reinforce this behaviour with approbation and supportive comments, complimenting with music and facial expressions to indicate that this behaviour during music making is desired/appropriate. In my work, I would prompt clients to engage in musical activities, e.g. I would ask a client to come strum my guitar and when they did so, I would begin singing a long as they were strumming and stop singing when they stopped strumming. I used frequent encouraging of instrument play during our activities.

'Sasuke would respond accurately to compliment my rhythms and so I would affirm this by engaging in eye contact, followed by verbally and physically praising him with a smile while repeating the rhythm back to him ... Sasuke would say he wanted to dance but would need a great deal of prompting... when Sasuke got up from the floor and stomp his foot in a soft by shy manner... I began stomping my feet to the 
rhythm of the music, and he followed me, increasing in volume.' (Sasuke's Clinical Notes, Session \#5 - 13/03/17)

\section{Engagement}

In the behavioural approach, the therapist aims to engage the client in a variety of activities during the session. Engagement and participation in activities is important to a behavioural approach, behavioural modification and change can only be implemented when the client is actively engaged in the session, and therefore the therapist attempts to use a variety of techniques such as redirection, modeling, positive reinforcement and structure to engage the client. In my work, I often attempted to engage the client by using positive reinforcement as evidenced in the excerpt taken from Tristan's clinical notes above.

\section{Redirection}

In behavioural music therapy, the therapist uses redirection as a method for redirecting atypical and non-productive behaviour. Redirecting a child toward an activity would help to address a predetermined goal (Berger, 2002). In my work, I would redirect client behaviour by turning the response into the related activity, e.g. the redirection of humming into an enjoyable musicmaking activity. If a client were to get distracted and wander off during a musical activity, I would use redirection by changing the direction of the music, changing the dynamics suddenly, stopping the music, verbally redirecting or physically redirecting.

'Desk bells were introduced but he did not show any particular interest for a sustained period of time, rather he'd use them as drums, beating them on the drum. I redirected this behaviour and modeled how to play on the desk bells and he would reciprocate briefly before returning to beating them on the floor drum. I redirected by introducing the autoharp nearer to the end of the session when he was strumming my guitar but became quite possessive and wouldn't let me share with him. Donburi seemed very interested in the autoharp, playing on it for over 5 minutes without any distractions. He seemed to really like the strumming aspect of it' (Donburi's Clinical Notes, Session \#14 - 27/05/17).

\subsection{Psychodynamic Approach}

I seldom drew on psychodynamic approaches in my practice, but it was evident that moments of catharsis indicated psychodynamic concepts unfolding in the session. Psychodynamic music therapy can offer some explanation and insights into experiences that unfold within the 
therapeutic relationship. A large spectrum of emotions can be contained during sessions in psychodynamic music therapy, as improvisation plays a special role in this approach, to allow the infinite forms of music to envelop the therapeutic atmosphere (Priestley, 1994). The findings showed that I only identified what appeared to be a psychodynamic approach during moments of containing, particularly during musical improvisations, as described below. My findings suggest the psychodynamic approach was not such a big feature of my practice. However, this may also be due to the fact that I was rarely approaching my practice with a psychodynamic standpoint to begin with and because I was also influenced by my co-therapists who were influenced primarily by a music- and client-centered framework.

\section{Containing}

In psychodynamic music therapy, containing is a function that the therapist uses to 'contain' the mental and emotional experiences of the client, providing a psychic container (Sutton, 2002). The therapist absorbs the various stimuli and emotions presented by the client, dwells upon them reflectively, attempts to make sense of them, and then reacts accordingly. It is through this process that overwhelming emotional mental feelings can be dealt with (De Backer, 1993). In my work, psychodynamic approaches would unfold during some emotional moments of sessions, where clients were experiencing a cathartic moment and I attempted to provide a psychic container. When a client began to experience a catharsis, I would provide a musical atmosphere using improvised music to hold the environment, where every form of communication was to be received by the therapist. I wondered if the emotionally charged music was able to unlock the repressed feelings of the client.

'I remained observant to any noticeable responses that I could match but I didn't allow this to be the drive of my musical momentum - I matched Yuri accordingly to what I felt too and I trusted in the music - his gaze affirmed this and I began to develop and expand the musical atmosphere. I noticed that Yuri became teary, but I was unsure what to make of it - I continued to match him with music on the guitar, attempting to contain the musical atmosphere and explore these feelings freely.' (Yugi's Session, Reflective Notes - 31/05/17) 


\subsection{Humanistic Approach}

This was the most common approach that underpinned my clinical practice. The humanistic model is what I felt predominantly orientated towards from previous clinical experiences. My way of thinking is partially justified by my understanding of the social constructs of disabilities, which is the belief that a person is more than just the sum of their parts. I highly valued the importance of a strong connection between the therapist and client. My personal background, training, and the facility that I worked in influenced these values. My reflective journal and clinical notes had affirmed my way of thinking during sessions, ultimately leading to a humanistic approach during sessions. Weekly and monthly supervision helped me retrospectively think and reflect upon my practice through discussion, reflection, and group improvisation. My intrinsic belief towards therapy centralises on accepting the client as they are, to be non-judgmental, and to have an unconditional positive regard towards clients. In my practice, I drew on humanistic approaches when I worked intuitively, provided a safe and stable environment for the client, and when I provided opportunities for choices.

\section{Client-led}

In music therapy, the humanistic approach emphasises free will, autonomy and client empowerment, therefore, the music therapist facilitates opportunities where the client is able to make informed or spontaneous decisions and have them respected and embraced by the therapist. In my work, I was often facilitating decision-making opportunities for clients, e.g. I would allow them to lead the session by matching the clients musically but not overpowering and presenting too many directives. Any directives presented had no focus towards behaviour modification, but towards encouragement of making decisions. Being client-led during session was also about listening attentively to the client and responding to and implemented the client's expressed suggestions. For example, a client would begin reaching for the drum during an activity that did not include drums, but I would facilitate this by bringing the drum closer and allowing the client to engage in drumming, modeling some instrument play. The use of visuals also showed to be effective in empowering clients to make decisions, such as choosing an activity or an instrument to play. I found that allowing the client opportunities to make decisions and choices also made me feel empowered; I felt very comfortable that our relationship seemed more equal. My work with Dennis involved a lot of client-led sessions, where I allowed sessions to take place in the 
comfort of his own room instead of the main music room, and also allowing him to be out of his wheelchair and roam freely. I placed emphasis on the here-and-now situation and focused on the therapeutic relation, and the understanding of his challenges and patterns (Wigram et al., 2002). Facilitating a client-led session also meant embracing moments of silence and allowing the silence to fill the room, rather than use it as an opportunity to lead the session.

'...Dennis became distracted with the guitar stand at this point so I decided to play a blues medley to grab his attention. He didn't seem to notice my playing too much, if not, at all. I stopped shortly after and moved closer to him where he was playing with guitar stand. I began playing on the xylophone, matching his movements and mood. He didn't seem too interested in the xylophone either, as he moved away to the other side of the room. I faded out to silence and went to join him on the floor without any instruments, patiently observing him. He frequented eye contact with me when I sat next to him. Later, he placed the guitar on my lap, in which I began to play 'Baa Baa black sheep' while he strummed and I played the chords. He continued strumming for a minute or so and then went to grab the guitar off me to try place it on the stand. I did not try to redirect this time, instead I accompanied his actions by matching him first on the drum with a waltzing rhythm and also vocalising some sounds. He would look over at me every time I sang his name, being able to sustain eye contact for a few seconds before resuming to his activities. I then went over to the piano to match him, also using vocalisations... He often looked over at me when I stopped playing... (Dennis' Clinical Notes, Session \#3 18/02/17)'

\section{Respect}

In humanistic music therapy, respect is a core component when working with clients. Humanism shares a respect for the person's subjective experiences. Respect is a prominent component in the literature of humanistic psychology and music therapy (Rogers, 1951; Maslow, 1968; Oldfield, 2006). Respect also meant respecting a client's preference for music, activities and choices. In a music therapy context, that means being able to respect any responses and behaviours that were presented to me, without judgement. In my work, I would present activities based on the interests of the client and also use music to match the client accordingly, without leading the way, but following the client's choices in music.

'Yugi's energy levels and mood seemed to be on the lower side of the spectrum, as evidenced by drowsy eyes and frequent yawns. He looked 'sadder' than usual.,. I omitted the greeting song and instead began improvising on some soft melodic progressions, using a gentle fingerpicking motion that matched his overall mood, using nuanced warm tones with very simple melodies' (Yugi's Clinical Notes, Session \#13 - 02/06/17) 
In this clinical excerpt, I respected my client's choices and decided to be flexible with my agenda, choosing to facilitate a musical atmosphere that was congruent with the client's mood, rather than to engage the client with activities, being goal-oriented. When things were not going as planned, I tended to shift my thinking towards the importance of a trusting relationship, and this allowed me to accept all of my client responses. Another excerpt below demonstrates the focus of the relationship over the goal-oriented thinking, or a humanistic approach over a behavioural approach.

'He lay in bed while I sat on the bedside playing a greeting song to him. He was seemingly preoccupied with a toy in his hand but I didn't try to take it from him. I decided to just play music and see if he would show any signs of responsiveness. He would make eye contact with me every now and then but only it would be very short-lived. Dennis crawled off his bed and towards the door, I went to redirect but he was persistent in leaving so I followed him into the main room and sat with him for a while before we concluded the session... I had prompted Dennis throughout the session to play on the drum and bell that was placed in front of him but he didn't seem interested at all, so instead I supported him while he lay in fetal position in bed.' (Dennis' Clinical Notes, Session \#4 - 24/02/17).

Here I sat next to the client during moments of prolong silence without feeling the tendency to take control of the atmosphere with music. I didn't anticipate any given responses, but instead just sat there to 'be with' the client. Respect can manifest in tailoring musical activities to suit the client's preference in music, or respecting the responses presented by the client.

\section{Trust}

Trust in a humanistic framework is to trust in the clients' choices, believing that those are choices that contribute to their journey of actualization and self-determinism. In my work, I placed trust in my clients' actions and responses, trusting in the relationship and in the client's decision-making. When a client had responded in a way I had not anticipated, but was conducive to building relationships and making music together, I would validate the response through eye contact, listening, matching or mirroring. The excerpt below showcases the component of trust manifesting within a humanistic music therapy approach.

'Dorian became increasingly distracted by the guitar stand and also began to notice me less. I decided to play an upbeat blues shuffle to grab his attention but he 
didn't seem to notice my playing too much, if at all. I stopped shortly after and moved closer to him where he was playing with the guitar and the stand. I began playing on the xylophone, matching his movements and mood. He didn't seem too interested in the xylophone either, as he moved away to the other side of the room. I faded out and went to join him on the floor without any instruments... with no attempt to redirect him, but instead observe him patiently' (Dorian's Clinical Notes, Session \#4 - 24/02/17).

In this excerpt with Dorian, I believed that he had demonstrated potential for self-growth so therefore trusted in his decision to engage with his own interests. When he had wandered off, I attempted to redirect him with music once but later, joined him on the floor with no expectations. I trusted what he wanted to do was okay, and also felt that there was nothing inherently wrong with doing so as the action was not harmful to anyone. The unconditional positive regard is the crux of humanistic music therapy, and that means placing great emphasis on building a trusting relationship. For clients to feel safe, there has to be a fair measure of trust between the therapist and client. Building a relationship with the client also means 'trusting' in the client to make informed decisions. The therapy environment has to be balanced so that the client is able to feel safe enough to take risks, but also have the containing properties of music creating the safety necessary for the uncertainty to be tolerated (Cobbett, 2016). If the atmosphere is too safe then the client won't take risks, but if it feels too dangerous then the client will feel overwhelmed.

\section{Engagement}

In humanistic approaches, the client and therapist engage in various ways of being, musically or verbally, to support self-actualization. In my work, I used engagement through musicing, attempting to create possibilities for being with others, with the premise of building closer relationships with my clients. While also focusing on the aesthetic dimensions of music, my purpose through musicing was to build a connection with the client. Of course, the musical qualities contributed a lot to this. I noticed my younger clients needed that extra enthusiasm and novelty in activities to be engaged. As a young child, it is normal to want to be involved in entertaining activities, so I had to radiate enthusiasm and constantly fuel the improvisations and activities with spontaneity and imagination. I found it easier to engage with my clients through improvisations as this allowed a lot of flexibility, safe risks and the opportunity to venture into uncharted territories. For example, I would initiate improvisations based on the overall mood and 
of the client and later, spontaneously introduce captivating rhythms to facilitate engagement. The sudden changes in musical elements would keep clients engaged. The focus of the improvisations was always towards the client and had the purpose of strengthening the relationship through music making. The use of the improvisation facilitates the freedom to express oneself, and spontaneous musical interactions support the developing therapeutic relationship (Warren, 1997). During the improvisations, I found myself implementing the matching technique. For example, if a client were boisterous and energetic, I might match the client's energy with an upbeat tempo, staccato accented notes, and an upward contouring melodic line, matching the client's movements and painting a landscape for the client. I used a variety of techniques to facilitate engagement with clients; using matching, mirroring, prompting and redirection, but all with the ultimate purpose of fostering a strong connection with the client.

'Donburi's participation was intermittent so instead of following the fixed session plan I had in mind, I proceeded to follow him around the room, matching him and facilitating music on his terms, i.e. when Donburi was pushing the drum around on the floor, I went onto the floor and played on the drum with him. This would seem to grab his attention and we would briefly play on the drum together before he moved onto something else' (Donburi's Clinical Notes, Session \#14 - 27/05/17).

\subsection{Summary of Findings}

Through the process of this research, four main approaches of music therapy were explored and various themes within each approach emerged. These themes showed what I was doing in my approach that was congruent with a particular framework. It was evident that my approach towards music therapy was very eclectic, but I held a personal philosophy of humanism, which influenced my ways of thinking in practice. Engagement with clients was a theme that emerged within all approaches, except the psychodynamic approach. My humanistic approach included facilitating of empowerment through client-led sessions; respect and trust towards the client in their choices; and lastly, facilitating engagement with clients through a variety of techniques. My behavioural approach manifested when I was goal-oriented and when I focused primarily on achieving benchmarks. I used a variety of techniques to engage the client, for the purpose of working towards their long-term goals. The techniques used within this approach were: modeling new behaviours, implementing structure within activities, positive reinforcement for desired behaviours, and redirection of unwanted behaviours. My music-centered approach included 
mirroring and matching clients musically, creating of aesthetic musical atmospheres with and for the client, and lastly, facilitating engagement with the use of musical elements. Music was the core of the therapy and it was from the intrinsic dimensions of music, where other moments could unfold. Finally, the psychodynamic approach manifested occasionally in my practice during moments of catharses with clients. When these moments arose, I had attempted to explore these turbulences by containing the cathartic experience; by providing a psychic container, I was able to explore the feelings of the client and myself safely in the session. 


\section{Clinical Vignette}

During my clinical placement, I worked with a wide range of clients with a range of disabilities in various settings. This clinical vignette aims to describe my individual therapy practice with Dylan, as well as highlighting the many themes that emerged through the course of our work together. Dylan was a 12-year-old boy who was diagnosed with Down Syndrome (DS). He had heart surgery at the age of six weeks and a tracheostomy in place until the age of 6 , which profoundly impacted his ability to communicate verbally. Dylan was referred to music therapy because his parents recognised his love for music. He was often dancing along to songs, and eagerly participating in instrument play during his initial consultation meeting. Dylan's parents hoped that music therapy would help with his vocalizations, and improved social and communication skills. An assessment period was held for 8 weeks to develop goals for Dylan. At the end of the assessment period, it was decided that sessions would work towards improved communications skills and sustained attention within presented activities. Observations during the first few weeks showed a variety of approaches to accommodate for Dylan's boisterous and playful nature. Goals were developed within a goal-oriented framework through observation of behavioural domains, such as communication and attention skills. The goals for Dylan were as follows:

\begin{tabular}{|c|c|}
\hline Long-term goal & $\begin{array}{l}\text { Short-term focus } \\
\text { (may be specific objectives or } \\
\text { broad areas for development) }\end{array}$ \\
\hline $\begin{array}{l}\text { 1. Dylan will develop improved } \\
\text { communication skills. }\end{array}$ & $\begin{array}{l}\text { a. Dylan will utilise picture symbols, gestures, sign language } \\
\text { and/or vocalizations to communicate his wants in the } \\
\text { music therapy session with minimal prompting on four } \\
\text { consecutive occasions. } \\
\text { b. Dylan will follow verbal directives and/or musical cues in } \\
\text { order to engage in social interactions (such as greetings, } \\
\text { turn taking and shared instrument play) with minimal } \\
\text { prompting on four consecutive occasions. }\end{array}$ \\
\hline $\begin{array}{l}\text { 2. Dylan will develop and } \\
\text { demonstrate improved } \\
\text { attention. }\end{array}$ & $\begin{array}{l}\text { a. Dylan will actively participate in each musical activity } \\
\text { presented with minimal prompting on four consecutive } \\
\text { occasions. } \\
\text { b. Dylan will maintain sustained instrument play during } \\
\text { structured musical activities with moderate prompting on } \\
\text { four consecutive occasions. }\end{array}$ \\
\hline
\end{tabular}


Clinical and reflective journal notes showed that I had used music-centered, humanistic, and behavioural approaches in my practice with Dylan. A typical session would follow a basic structure of a greeting song, a variety of pre-composed songs and improvisations, and then would close with a farewell song. All presented activities were used as a means to address Dylan's goals, i.e. a presented song would include a variety of activities and directives that facilitated sustained engagement, shared instrument play and opportunities for vocalizations.

A few weeks after our assessment period, Dylan had been displaying what I initially had interpreted as a defiance of authority, evidenced by being unable to follow directives during presented activities, where he would usually be able to do so with ease; and also wandering off to 'push' instruments around the room in a disorderly manner, without paying any attention to the musical atmosphere or therapist, e.g. he would push around the big gathering drum as if it were a vehicle and bang it against the walls or into other instruments, sometimes causing them to tip over. At first, when he would become distracted and walk off during an activity, I would try to grab his attention with rhythmically captivating tunes on the guitar, but this seemed to be ineffective. Later, I tried prompting more frequently than usual, followed by positive reinforcement, but Dylan seemed to have inhabited this private world of his. At one point, I attempted to authoritatively removing the instruments he was pushing around, but this only resulted in increased restlessness, as characterised by becoming more and more possessive of other instruments and not allowing me near his space. I felt that sessions were regressing rapidly and sought advice from my clinical supervisor, where I talked about my challenges during the past few sessions and so we reviewed the clinical footage together and attempted to analyse and interpret what was going on during sessions. My supervisor had suggested that I evaluate not just what is happening externally, but what might be happening internally, in other words, instead of being frantic and worrying so much about myself or my client's attempt to overthrow the structure. Instead, I could focus more on the client's responses as an indication of what they might be communicating. My reflective and supervision notes during this period indicated that I was focusing on a behavioural approach, focusing on structured activities and using techniques such as prompting, directives, redirection, and positive reinforcement. It was seen that my way of 
thinking was towards behavioural modification, to encourage 'desired' behaviours and therefore, eliminate any unwanted behaviours that manifested in the session.

'This session was overall a very startled session today. I had followed routine in session as usual, but Dylan seemed to be disinterested. He had been actively engaged in our greeting song, following directives with minimal to moderate prompting. After the greeting song, Dylan's attention seemed to soar downwards and he was not able to follow any directives without maximum prompting. He had been tipping over instruments throughout the room... He attempted to overthrow the structure and would not listen to me... tried plenty of redirection and prompting.' (Dylan's Clinical Notes, Session \#12 - 13/05/2017).

Upon introspective review of the footage, I realised I was being very firm and resistant myself; I focused so much on progression of goals that I had momentarily boxed myself up in a particular mindset. I noticed that I had perceived Dylan's actions as being 'negative' and therefore tried to manage it with a behavioural approach. There was nothing inherently wrong with Dylan's behaviour as neither of us were physically jeopardised or endangered by the behaviour. I focused on trying to get Dylan to play the instrument "correctly" when there is really no "correct" or "incorrect" way of playing an instrument.

The following session, Dylan attempted to 'overthrow' the structure by wandering off midactivity and pushing the big gathering drum around. Instead of attempting to 'correct' his perceived behavioural problems, I put down my guitar and went onto the floor with him and pushed it with him. While doing this, I sang a song that reflected what we were doing. In Dylan's actions, there was a pattern I was able to identify, which allowed me create a theme and activity based on his actions. Dylan was rolling the drum on its side, tipping it over upside down and then putting his head inside the sound box, and he would repeat this over and over again. I created a song that involved an activity to each corresponding side he placed the drum on, for instance, when Dylan placed the drum 'sideways' we would roll back and forth singing we're rolling, rolling, rolling, rolling; when the drum was flipped 'under' (upside down) we would put our heads inside and vocalise la-la-la; and lastly, when it was on its 'top' side we would drum as long as we could until I said STOP. This activity turned out to be an excellent motivator for Dylan as we could continue working towards his goals and at the same time, I didn't have to expect Dylan to 'conform' to the structure in mind. I managed to redirect Dylan's behaviour toward an activity addressing a predetermined goal, or at least facilitate the therapeutic 
relationship in order to work towards them at a later stage. Redirecting a behaviour into something functional is not delineating a 'wrong' behaviour per se, but rather to redirect any given behaviour into a more positive one. Dropping possessive and defiant behaviours, Dylan began to be more playfully assertive and musically engaged with me. His vocalisations and entire bodily expression revealed a high-spirited boy who was really enjoying music in the way he wanted. From this experience I learned, despite having a strict and meticulously planned out session structure, the need to be actively flexible in agenda. Dylan didn't need me to 'tell him what to do' all of the time. Music therapy is supposed to be a safe and free atmosphere for Dylan to be explorative and his perceived 'behaviours' were not at all destructive to himself, the instruments or me. Knowing this, I allowed Dylan to take lead of the session and have him make choices, where I could support his freedom of self-expression and exploration in the therapy room. Looking back at our sessions together, I had initially approached the session from a behavioural perspective, focusing on 'correcting behaviour' and having Dylan doing what was I had expected of him. Whereas, later I took a more humanistic and music-centered perspective, allowing Dylan just 'to be' in session and just support him in whatever way I could. This clinical excerpt showcases this shift in thinking very well.

'Our session was mostly intended to be a behaviourally-structured session with fixed activities and goal-focused approaches but later in the blues, I found I totally let myself go and allowed the client to 'let go' too but at the same time, maintaining these 'already set boundaries'. It was a very fruitful improvisation, lasting almost 1/3 of the session and nothing was planned, everything was absolutely in the spirit of spontaneity. Most of my beliefs are around humanistic psychology and allowing the client to discover himself, around self-determination and I believed that my client had it in him. I also realised how many behaviour modification techniques I routinely began to use in some of my other sessions (Dylan's Clinical Notes, Session \#17 - 17/06/2017).

The humanistic approach is informed by humanistic theories and focuses on encouraging freedom of self-expression in musical identity (McFerran, 2009). A developmental 'behavioural' approach tends to be more goal driven, organised in structure of session to facilitate the acquisition of particular skills and relying on music to provide a motivational framework as well as positive rewards for achievements (Wheeler, 2008). McFerran \& Shoemark (2013) suggest that for children with very complex needs, the focus of music therapy should be on achievable goals such as fostering meaningful relationships, rather than focusing primarily on 
developmental goals. As relationships have direct impact on the development and wellbeing of a client, it should be typically regarded as being equal importance to musical experience.

\section{Discussion}

"Which music therapy approaches do I draw on when working with a wide range of clients in various settings?"

\subsection{Music Therapy Approaches}

Throughout this research study, my inquiry into my clinical practice predominantly revolved around how I effectively engaged with my clients and addressed their goals, and also how I could continue to foster a strong client-therapist relationship with my clients through music therapy. Prior to this research, I had not critically examined my practice in regards to a specific approach but naturally based my practice on my philosophical orientations and the needs of the client. I had not expected my approach to be so goal-oriented when I thought about working towards goals. I had anticipated that humanistic perspectives would largely influence my approaches, but through my findings, I was surprised to see how much I also drew on other approaches. For example, I drew on behavioural approaches when I focused primarily on working towards goals, and also when a client was displaying challenging behaviours. I was surprised to see that when using a behavioural approach, my way of thinking went against the notion of humanistic thinking, i.e. I would focus on behavioural modification and redirecting the client into what I had strictly planned out for the session. Furthermore, when analysing my clinical data, I had not expected to see the stark perceptual contrast in my approaches when working with clients. I had anticipated that each client I worked with would use one given approach based on their needs and what I thought was best for them. My findings demonstrated that one could use a variety of approaches with just one client as sessions progressed; it showed that I often alternated in approach, and that one single session could draw on various approaches and ways of thinking.

My findings suggested that I often employed a humanistic framework in my practice and drew on other techniques when necessary, for example, redirection, positive reinforcement, and 
matching. Scovel \& Gardstrom (2005) mention that humanistic frameworks have been applied to both music therapy assessment as well as treatment. A case study featuring a humanistic approach towards clients with behavioural issues showcased how a humanistic framework was used towards managing behavioural issues (Aigen, 1991). My ways of thinking differed depending on how I thought about working towards the goals. My supervision meetings influenced these approaches I used during session as I often asked for constructive feedback from my clinical supervisor. Although I had an awareness of my practice being humanistically informed, I was surprised at how often I alternated in my approaches. I also noticed that I highly valued the client-therapist relationship, even when using other approaches. Using approaches within a humanistic framework helped me build and strengthen relationships, a core component in therapy and a belief that was congruent with my philosophical orientation. Determining a therapeutic approach meant knowing and understanding the client; knowing and understanding the client meant the focus of therapy being towards the therapeutic relationship. I found that when the focus or aim of the session changed, so did the therapeutic approach; meaning that one moment during therapy I could have used a music-centered approach, and another moment using a humanistic approach. It was not just the therapist's orientation or preference that determined the therapeutic approach, but also the contributing factor of the client's relationship with the therapist. Directly employing a behavioural approach meant that the therapeutic relationship was slower in development, whereas building on the relationship at first, facilitated the growth of the relationship; which in turn, allowed other approaches to be employed in the session.

Psychodynamic approaches unfolded through the transference and countertransference experienced during sessions with clients. As these moments rarely unfolded, I was not able to draw a strong link between the contexts, approaches and the clients. However, the findings suggested that I perceived psychodynamic approaches occurring during moments of catharsis. The exploration of my own feelings also helped with determining which approach I might have been using. I was surprised to see that the theoretical formulation of psychodynamic music therapy is also to facilitate engagement of the client that will ultimately tap into their 'core creativity, personality, and inner-self' (Wheeler, 2015, p. 140). The containing that occurred during session was then, also a form of engagement; something I had not coded during my analysis stage but have now found closely linked. One of the ways in which I was able to 
recognise psychodynamically informed moments was through my body of knowledge pertaining to psychodynamic music therapy, and its transference and countertransference. Winnicott (1971) states that it is only in [musical interactions] that the client is able to be creative and utilise the whole personality, and it is only through creativity that the client discovers the self. Thus, psychodynamic moments would manifest through the platform of engagement in musical experiences. In other words, my findings suggest that the moments of psychodynamic containment that unfolded during my practice had emerged from a music-centered interaction... or at least, through the platform of engagement. Whether the engagement with the client was facilitated initially from a psychodynamic perspective is not clear, but it is important to consider transference and countertransference being prevalent in cathartic musical experiences (Priestley, 1994).

\subsection{Contexts}

It is crucial to highlight the contexts in which I worked in, recognizing the various contributing factors that could influence my approach towards practice. My philosophical orientations, the facility and client needs greatly influenced the approach used. I discovered the findings were somewhat congruent with the way I thought about practice prior to this research study. It seemed that my practice seemed to be predominantly musical, but also included non-musical modes of communication. The facility I was on placement on had developed a system in monitoring goals and objectives (See Appendix F - Example of Clinical Notes \& Appendix G - Example of Goal Sheet) and through ongoing supervision of my sessions with clinical supervisor, I was surprised to see a behaviourally informed way of practicing with clients who demonstrated challenging behaviour. I believe this was justified by the ongoing reflection and reviewing of clinical footage, supervision meetings and also review meetings with the clients' parents/caregivers. Parents usually looked forward to improvement on more 'tangible' domains such as improved attention, communication and reciprocal interactions. I predominantly used a more humanistic approach in my work at the healthcare facility with young adults, as the facility valued a more person-centered philosophy. Furthermore, the flexibility I had when working at the healthcare facility provided me the opportunity to work with the clients naturally without any impositions from the facility procedures and documentation. Through my findings, I found that I would alternate between a music-centered and a humanistic approach when working with the clients at 
the healthcare facility, as the clients were nonverbal and thus, music was the primary vehicle of communication. I believe ongoing reflection and awareness of the contexts was important in how it influenced my practice.

\subsection{Relationships between Approaches and Contexts}

I happened to use matching a lot more with my clients with autism spectrum disorder (ASD) as I found it to be a non-invasive and flexible way of interacting with them. Matching allowed me to accommodate for any sensory integration in clients with autism. Sensory integration challenges play a prominent role in autistic processing and manifesting behaviours. Thus, the way in which I observed behaviours was very important in determining the most congruent approach. Possessing an awareness of the sensory integration and physiological process relevant to autism helped me with designing goals, objectives and strategies for treatment. I found mirroring to be invasive at times and had to transition to matching in order to be able to interact with the client on a mutual level. I happened to use both a humanistic and music-centered approach towards clients with autism, often noticing that I used nonverbal forms of communication during sessions, as the music seemed to facilitate most of the interactions. Supporting literature has shown that the use of music can be highly effective with clients with autism spectrum disorder (Whipple, 2004; Gold, Wigram, \& Elefant, 2010; Gold, 2011; Geretsegger, Elefant, Mossler, \& Gold, 2014). Examining my work with clients with Down syndrome (DS), I noticed I predominantly gravitated towards a more behavioural approach, as goals tended to focus on behavioural modification and integration into settings outside of therapy. Thus, these sessions needed a great deal of meticulous planning and structured activities in order to work towards those goals. I mainly used humanistic and music-centered approaches at the healthcare facility with young adults with neurological disabilities, sometimes drawing on behavioural techniques, but generally focusing on fostering rapport with the client and allowing greater flexibility in sessions. Literature pertaining to this client population within music therapy identifies the challenges that may arise in this client population (Bradt, Magee, Dileo, Wheeler, \& McGilloway, 2010; Thaut, 2010; Baker, Wigram, \& Gold, 2005). People living with neurological conditions often have various challenges, such as speech and language barriers, loss of movement, and ongoing physical pain. These symptoms can often lead to psychosocial challenges such as low mood, anxiety and depression (Thaut \& Hoemberg, 2014). Using pre- 
composed and familiar songs tailored to the client's taste of music was a very effective way of engaging with the client. These activities would facilitate vocalisations, and the opportunity to venture into improvisations.

\subsection{Shared Theoretical Concepts}

In my findings, it was clear that a shared conceptual framework was seen with 'engagement' emerging in three out of four approaches that were used. Through these three theoretical lenses it became clear that engaging the client was crucial in facilitating growth of the therapeutic relationship. In a music-centered approach, I was engaging clients through improvised music, using the musical atmosphere as a platform for therapeutic growth. The thinking behind this style of engagement was almost always associated with a music-centered way of thinking, where engagement was initiated through musicing. In a humanistic approach, I engaged clients with the focus of facilitating a client-led session, that is, allowing space, listening, and waiting through music. While I still kept the aesthetic dimensions of music in mind, engagement with the client unfolded through silence, verbal and non-verbal interactions, as well as musical interaction. In a behavioral approach, engagement was initiated through structured activities. I often attempted to engage the client through behavioural techniques such as modeling, positive reinforcement and redirection. Spontaneous musical interactions would still unfold, however verbal interaction through modeling and redirection was usually how I engaged my clients when using a behavioural approach. Although the concept of 'engagement' through each approach had different interventions to engage the client, musical interaction was one shared concept that was used throughout all the approaches. Musical interaction could be used to engage a client but that did not mean that it was regarded as music-centered approach, rather it was the ways of thinking that determined which approach I had used to engage the client. 


\subsection{Strengths and Limitations of the Study}

One of the distinctive aspects of the research was being able to investigate my own clinical practice. This also meant the acknowledgement of the researcher-practitioner relationship and how it may impact the research, as this qualitative study is inherently subjective. The researcherpractitioner role means that the data expresses my own interpretations, thoughts, and opinions of what I thought was relevant or significant to my practice, in terms of my approach. The constructivist approach towards the study helped set these boundaries. The subjective element of this study also meant limitations to generalizability, as these are my own interpretations of what I observed and experienced. My interpretation of the data is informed by my knowledge of relevant literature in music therapy, as well as the knowledge of my client population and their respective clinical settings. Conversely, the small number of participants may be considered a limitation due the research lacking breadth, as it only gives a partial insight into clinical practice. Qualitative findings cannot be generalised to other populations. The client population did vary greatly, including clinical settings being in two contrasting settings. Further, I was relying on my usual practice documentation, which may have been sparser than data specifically collected for research. Analysing video data would have filled some of the missing gaps, although analyzing video footage requires an extensive amount of time, and because I was working with such a wide range of clients over many sessions, it was not practical to thoroughly analyse every session during the placement period. The findings have generated a greater understanding of my clinical practice and how I utilise music therapy approaches to support my clients. It is hoped that this may invite other music therapists to reflect on their practice in regards to music therapy approaches with diversity in client populations and settings.

\subsection{Recommendations}

This research study has illustrated how I am able to resource my clients using approaches that are most congruent with ways of thinking, and more importantly the client needs. As this research study was based on a rather small data set, working with a larger population over an extended period of time, with the addition of video analysis, would ultimately provide a greater understanding of how I can effectively engage clients within a wider range of clinical settings. The relevance of this research was limited to the placement facility and the outreach healthcare 
facility. Thus, recommendations for future research should explore the broader practice of music therapists to ascertain any coherent themes that have emerged in this research study. Continuing the discourse in music therapy approaches is crucial in improving clinical practice across the field of music therapy, as well as providing insight for related health and education professionals. Having the opportunity to observe a wide range of clients in various settings is beneficial to how we can improve our practice. Also, further research in music therapy approaches and their contextual relationships to each other will provide helpful to music therapists. 


\section{Conclusion}

This research aimed to investigate the different music therapy approaches utilised with a wide a range of clients in various clinical settings. As there are many variables that influence how a single approach is used, it is important to be flexible in approach to meet the diversity in practice. A humanistic framework predominantly guided the approaches I drew on with a wide range of clients in various settings. This was influenced by personal contexts as well as the facility I worked in. I found that I highly valued the therapeutic relationship between the client and therapist, as it allowed me to understand my client more intimately, and also to create many opportunities of meaningful moments together. Throughout this research study, I found that a range of techniques could be implemented within any given approach, as long as the approach was congruent with the purpose the approach strived to attain. The use of behavioural techniques, such as modeling, can still be used within a humanistic or music-centered approach, as long as the way of thinking remains congruent with the approach used. I could model specific words or any instrument for a client to imitate specific actions, in order to work towards goals, i.e. increased vocalisations and speech. The client and I could create an atmosphere together filled with decision-making opportunities and freedom of self-expression. Moreover, these concepts all relate to the realm of engagement with clients. Engagement was fundamentally the impetus to music therapy sessions and thus, resulted in various techniques being implemented to engage the client. That is, the various techniques employed had an overlying purpose of engaging with the client, and an underlying purpose of building a relationship, working towards goals, or exploring emotional realms. Music-centered approaches often manifested during spontaneous improvisations and musical interactions with my clients. Music was always the core

of therapy during a music-centered approach, and the musical experiences that unfolded were developed, strengthened and explored further. I drew on behavioural approaches when working towards specific goals, however behavioural techniques were also used to facilitate or sustain engagement within a humanistic framework. Introducing activities that were in the best interests of the client, improvisation and instrument play, were great motivators for clients and a great way to work towards goals, while still respecting their preferences. Both music-centered and humanistic approaches were useful in facilitating freedom of self-expression musically and nonmusically. Individualised activities, pre-composed song, or improvisations were able to provide a supportive musical atmosphere to allow the client to feel safe and engage in musical interaction. 
This research has reinforced my understanding of the many different aspects of thinking that goes into my music therapy practice, especially the way I interact with my clients and specifically how I approach my own work and why I do so. The qualitative nature of this research means that it cannot be generalised beyond the contexts in which it takes place. However, it does provide insight into some ways of thinking in music therapy practice, and may encourage others to reflect on their own practice regarding how they are able to facilitate growth in a therapeutic environment. 


\section{References}

Abrams, B. (2010). Evidence-based music therapy practice: An integral understanding. Journal of Music Therapy, 47(4), 351-379.

Abrams, B. (2014). Humanistic approaches. In B. L. Wheeler (Ed.), Music therapy handbook (pp. 148-160). New York, NY: Guilford Publications.

Aigen, K. (1991). Creative fantasy, music and lyric improvisation with a gifted, acting-out boy. In K. E. Bruscia (Ed.), Case studies in music therapy (pp. 109-126). Gilsum, NH: Barcelona.

Aigen, K. (1995). An Aesthetic Foundation of Clinical Theory: An Underlying Basis of Creative Music Therapy. In C. B. Kenny (Ed.) Listening, Playing, Creating: Essays on the Power of Sound (pp. 233-257). Albany, NY: State University of New York Press.

Aigen, K. (1999). The true nature of music-centred theory. British Journal of Music Therapy, 13(2), 77-82.

Aigen, K. (2005). Music-centred music therapy. Gilsum, NH: Barcelona Publishers.

Alberto, P. A., \& Troutman, A. C. (1995). Applied behaviour analysis for teachers (4th ed.). Englewood Cliffs, NJ: Prentice Hall.

Alvin, J. (1975). Music therapy (revised edition). London: John Claire Books.

Ansdell, G. (1995). Music for Life: Aspects of Creative Music Therapy and Adult Clients. London and Philadelphia: Jessica Kingsley Publishers.

Ansdell, G., \& Pavlicevic, M. (2004). Community music therapy (1st ed.). London, NY: Jessica Kingsley Publishers.

Austin, D. (1999). Vocal improvisation in analytically oriented music therapy with adults. In T. Wigram and J. De Backer (Eds). Clinical Applications of Music Therapy in Psychiatry. London: Jessica Kingsley Publishers.

Baker, F., Wigram, T., \& Gold, C. (2005). The effects of a song-singing programme on the affective speaking intonation of people with traumatic brain injury. Brain Injury, 19(7), 519-528. doi:10.1080/02699050400005150

Baruth L. G., \& Huber, C. H. (1985). Counseling and psychotherapy: Theoretical analyses and skills application. Columbus: Merrill Publication.

Baker, F. (2015). What about the music? Music therapists' perspectives on the role of music in the therapeutic songwriting process. Psychology of Music. 43(1). 122-139. DOI: $10.1177 / 0305735613498919$. 
Berger, D. S. (2002). Music Therapy, Sensory Integration and the Autistic Child. London: Jessica Kingsley Publishers.

Bion, W. (1962). Learning From Experience. London: Karnac Books.

Bradt, J., Magee, W. L., Dileo, C., Wheeler, B. L., \& McGilloway, E. (2010). Music therapy for acquired brain injury. Cochrane Database of Systematic Reviews, 2010(7), CD006787.

Brown, D., \& Peddar, J. (1991). Introduction to psychotherapy: An outline of psychodynamic principles and practice (2nd ed.). London: Routledge.

Bruscia, K. (1987). Improvisational models of music therapy. Springfield, USA: C.C. Thomas.

Bruscia, K. (1998). Defining Music Therapy (2nd ed.). University Park: Barcelona Publishers.

Bruscia, K. (1998b). The dynamics of music psychotherapy. Gilsum, NH: Barcelona Publishers.

Braun, V., \& Clarke, V. (2006). Using thematic analysis in psychology. Qualitative Research in Psychology, 3(2), 77-101.

Bugental, J. (1964). The third force in psychology. Journal of Humanistic Psychology, 4(1), 1926.

Bunt, L., \& Hoskyns, S. (Eds.). (2002). The Handbook of Music Therapy. UK: BrunnerRoutledge.

Bunt, L., \& Stige, B. (2014). Music Therapy: An Art Beyond Words (2nd ed). London: Routledge.

Bunt, L. (1994). Music Therapy: An Art Beyond Words. London: Routledge.

Choi, B. (2008). Awareness of Music Therapy Practices and Factors Influencing Specific Theoretical Approaches. Journal of Music Therapy, 45(1), 93-109.

Cobbett, S. (2016). Context and relationships: Using the systemic approach with music therapy in work with children, adolescents and their families. British Journal of Music Therapy, 30(2), 65-73.

Corey, G. (2009). Theory and Practice of Counselling ( $8^{\text {th }}$ ed). USA: Thomson Books.

Corsini, R. J., \& Wedding, D. (Eds.). (2005). Current psychotherapies. Belmont, CA: Thomson Learning.

Crotty, M. (1998). The Foundations of Social Research: Meaning and Perspective in the Research Process. UK: Allen \& Unwin.

De Backer, J. (1993). 'Containment in music therapy.' In M. Heal and T. Wigram (Eds.). Music Therapy in Health and Education. UK: Jessica Kingsley Publisers. 
Darrow, A. (2008). Introduction to approaches in music therapy / edited by Alice-Ann Darrow (2nd ed.). Silver Spring, MD: American Music Therapy Association.

Darnley-Smith, R., \& Patey, H. (2003). Music therapy. London: SAGE Publishers.

Davis, W. B., Gfeller, K.E., \& Thaut, M.H. (2008). An Introduction to Music Therapy: Theory and Practice (3rd ed). USA: AMTA Association.

Edwards, J. (2005). Possibilities and problems for evidence based practice in music therapy. The Arts in Psychotherapy, 32, 293-301. doi: 10.1016/j.aip.2005.04.004

Eschen, J. T. (2002). Analytical music therapy. London: Jessica Kingsley Publishers.

Finlay, L. (2015). Relational Integrative Psychotherapy: Process and Theory in Practice, Chichester, Sussex: Wiley.

Frankl, V. E. (1967). Psychotherapy and existentialism. New York: Oxford University Press.

Freud, S. (1915). Observation on transference love. Standard Edition, 9. London: Hogarth Press.

Gaston, T. (1964) The aesthetic experience and biological man. Journal of Music Therapy 1(1), $1-7$.

Gaston, E. T. (Ed.). (1968). Music in therapy. New York, NY: MacMillan.

Gold, C., Wigram, T., Elefant, C. (2010). Music therapy for autistic spectrum disorder. Cochrane Databse of Systematic Reviews, $2010(2)$, CD004381.

Grocke, D., \& Wigram, T. (2007). Receptive Methods in Music Therapy: Techniques and Clinical Applications for Music Therapy Clinicians, Educators and Students. London: Jessica Kingsley.

Hadley, S. (1998). Transference experiences in two forms of improvisational music therapy. In K. E. Bruscia (Ed.), The dynamics of music psychotherapy. Gilsum, NH: Barcelona Publishers.

Hadley, S. (2003). Psychodynamic music therapy: Case studies. Gilsum, NH: Barcelona Publishers.

Hanser, S. B., \& Mandel, S. E. (2010). Manage your stress and pain through music. Boston: Berklee Press.

Heal, M., \& Wigram, T. (1993). Music Therapy in Health and Education. UK: Jessica Kingsley Publishers.

Heaton, J. (2004). Reworking Qualitative Data. USA: SAGE Publications.

Herron, D.G. (1989). Secondary data analysis: Research method for the CNS. Clinical Nurse Specialist, 3(2), 66-69. 
Hubble, M.A., Duncan, B.L., \& Miller, S.D. (1999). The Heart and Soul of Change: What Works in Therapy. Washington, DC: American Psychological Press.

Isenberg, C., Goldberg, F., \& Dvorkin, J. (2008). Psychodymamic approach to music therapy. In A.A. Darrow (Ed.), Introduction to approaches in music therapy (2nd ed., pp. 79-104). Silver Spring, MD: American Music Therapy Association.

Isenberg-Grzeda, C. (1996, July). Transference and transference resistance in guided imagery and music training. Paper presented at the meeting of the International Congress of the World Education of Music Therapy, Hamburg, Germany.

Kirkland, K. (2013). International Dictionary of Music Therapy. UK: Routledge.

Langdon, G. S. (1995). The power of silence in music therapy. In C. Kenny (Ed.), Listening, Playing and Creating: Essays on the Power of Sound. (pp. 65 - 69). Albany, NY: State University of New York Press.

Lecourt, E. (2004). The psychic functions of music. Nordic Journal of Music Therapy, 13, 154160.

Leonard, G. B. (1987). The transformation: A guide to the inevitable changes in humankind. New York: J. P. Tarcher.

Madsen, C. K., Cotter, V., \& Madsen, C.H. (1968). A Behavioural Approach to Music Therapy. Journal of Music Therapy, 5(1), 69-71.

Madsen, C. H., \& Madsen, C. K. (1998). Teaching/Discipline: A positive approach for educational development ( $4^{\text {th }}$ ed.) Raleigh, NC: Contemporary Publishing.

Madson, C. K. (1999). A behavioural approach to music therapy. Founding Model Address to the General Assembly, $9^{\text {th }}$ Word Congress of Music Therapy, Washington, DC.

Maslow, A. H. (1968). Toward a Psychology of being. New York: D. Van Nostrand Company.

McFerran, K., \& Shoemark, H. (2013). How musical engagement promotes well-being in education contexts: The case of a young man with profound and multiple disabilities. International Journal of Qualitative Studies on Health and WellBeing, 8(1).

McFerran, K. (2010). Adolescents, music and music therapy : methods and techniques for clinicians, educators and students. Retrieved from https://ebookcentral.proquest.com

McFerran, K. (2003). Contemplating the nature of adolescent group improvisations. Voices: $A$ World Forum for Music Therapy. Retrieved from www.voices.no/mainissues/mi40003000128.html

Meadows, A. (2011). Developments in music therapy practice: Case study perspectives. Gilsum, NH: Barcelona Publishers. 
Milton, M. (2010). Therapy and Beyond: Counselling Psychology Contributions to Therapeutic and Social Issues. NJ: John Wiley and Sons Publishing.

Music Therapy New Zealand. (2012). Code of ethics for the practice of music therapy in New Zealand. Retrieved from www.musictherapy.org.nz/documents/Code-of-Ethics-2012.pdf

Nelson-Jones, R. (2003). Practical Counselling and Helping Skills. USA: SAGE Publications.

Nordoff, P., \& Robbins, C. (1965). Music therapy for handicapped children. Blauvelt, NY: Rudolf Steiner Publications.

Nordoff, P., \& Robbins, C. (1977). Creative music therapy: Individualized treatment for the handicapped child. New York, NY: John Day.

Nordoff, P. \& Robbins, C. (2007). Creative Music Therapy: A Guide to Fostering Clinical Musicianship. Gilsum, NH: Barcelona Publishers.

Noy, P. (1966). The psychodynamic meaning of music: Part I: a critical review of the psychoanalytic and related literature. Journal of Music Therapy, 3, 126-135.

Oldfield, A. (2006). Interactive music therapy: a positive approach: music therapy at a child development centre (1st ed.). London Philadelphia: Jessica Kingsley Publishers

Oldfield, A. (2008). Working in partnership and supporting parents: music therapy for pre-school children and their parents at a child development centre. In A. Oldfield \& C. Flower (Ed.), Music Therapy with Children and their Family (pp. 19-36). Philadelphia: Jessica Kingsley Publisher.

Pavlicevic, M. (1997). Music Therapy in Context: Music, Meaning and Relationship. UK: Jessica Kingsley Publishers.

Pavlicevic, M., \& Ansdell, G. (2004). Community music therapy. London, England: Jessica Kingsley Publishers.

Priestley, M. (1994). Essays on analytical music therapy. Phoenixville, PA: Barcelona Publishers.

Riegler A. (2012) Constructivism. In: L'Abate L. (Eds.). Paradigms in Theory Construction. (pp. 235-255). Springer, New York, NY.

Robbins, C. (1993). The creative processes are universal. In: M. Heal and T. Wigram (Eds.), Music Therapy in Health and Education, pp. 7-25. London: Jessica Kingsley Publishers.

Rogers, C. R. (1951). Client-centered therapy: Its current practice, implications, and theory. London, England: Constable.

Rogers, C. (1995). On Becoming a Person: A Therapist's View of Psychotherapy. New York: Houghton Mifflin Company. 
Ruud, E. (2010). Music therapy: A perspective from the humanities. Gilsum, NH: Barcelona.

Ruud, E. (1980). Music therapy and its relationship to current treatment theories. Gilsum, NH: Barcelona.

Ruud, E. (1997). Music and the quality of life. Nordic Journal of Music Therapy, 6, 86-97. DOI: 10.1080/08098139709477902.

Scovel, M., \& Gardstrom, S. (2012). Music therapy within the context of psychotherapeutic models. In: R. Unkefer and M. Thaut (eds.), Music Therapy in the Treatment of Adults with Mental Disorders: Theoretical Bases and Clinical Interventions (pp. 117-132). Gilsum NH: Barcelona Publishers.

Shally-Jansen, M. (2013). Mental Health Care Issues in America: An Encyclopedia, Volume 1. USA: ABC-CLIO.

Silverman, M. J. (2007). Evaluating current trends in psychiatric music therapy: a descriptive analysis. Journal of Music Therapy, 44(4).

Small, C. (1998). Musicking: The meanings of performing and listening. Hanover: University Press of New England.

Smither, R. (2009). Existential and Humanistic Pyschotherapies. In D. C. S. Richard and S. K. Huprich (Eds.), Clinical Psychology: Assessment, Treatment, and Research (pp. 309328). Burlington, MA: Elsevier.

Stein, A. (1999). Well-Tempered bagatelles - a meditation on listening in psychoanalysis and music. Amer. Imago, 56(4), 389-416

Sutton, J. P. (2002). Music, Music Therapy and Trauma: International Perspectives. UK: Jessica Kingsley Publishers.

Thaut, M. H. (1999). Music therapy in neurological rehabilitation. In W. B. Davis, K E. Gfeller, Sc M. M. Thaut (Eds.), An introduction to music therapy: Theory and practice (2nd ed.; pp. 221-247). Dubuque, IA: McGraw-Hill.

Thaut, M. H. (2010). Neurologic music therapy in cognitive rehabilitation: Music listening and music making in the treatment of neurological disorders and impairments (report). Music Perception, 27(4), 281-285.

Thaut, M. H., \& Hoemberg, V. (Eds.). (2014). Handbook of neurologic music therapy. Oxford, United Kingdom: Oxford University Press.

Tsiris, G. (2008). Aesthetic Experience and Transformation in Music Therapy: A Critical Essay. Voices: A World Forum For Music Therapy, 8(3). doi:10.15845/voices.v8i3.416 
Unkefer, R., \& Thaut, M. (2002). Music Therapy in the Treatment of Adults with Mental Disorders: Theoretical Bases and Clinical Interventions. Gilsum NH: Barcelona Publishers.

Victoria University of Wellington. (2017). Human ethics policy. Retrieved from http://www.victoria.ac.nz/documents/policy/research-policy/human-ethics-policy.pdf

Warren, P. (1997). Music Therapy with a Child with Cerebral Palsy: A Case Study. Annual Journal of the New Zealand Society for Music Therapy, 31, 29-43.

Weissmann, G. (2008). Citizen Pinel and the Madman at Bellevue. The FASEB Journal, 22(5), 1289-1293.

Wheeler, B. L., \& Kenny, C. (2005). Principles of qualitative research. In B. L. Wheeler ( $2^{\text {nd }}$ ed.). Music Therapy Research, pp. 50-71. Gilsum, NH: Barcelona Publishers.

Wheeler, B. L. (2005). Music therapy research / edited by Barbara L. Wheeler. (2 $2^{\text {nd }}$ ed.) Gilsum, N.H. Barcelona

Wheeler, B. L. (2008). Edith Lecourt interviewed by Barbara Wheeler. Voices: A World Forum for Music Therapy, 8(3). Retrieved from https://normt.uib.no/index.php/voices/article/ view/425/349

Wheeler, B. L. (Eds.). (2015). Music Therapy Handbook. New York, NY: Guilford Press.

Whipple, J. (2004). Music in intervention for children and adolescents with autism: A metaanalysis. Journal of Music Therapy, 41(2), 90-106.

Wigram, T., Wosch, T., \& ProQuest. (2007). Microanalysis in music therapy: Methods, techniques and applications for clinicians, researchers, educators and students / edited by Thomas Wosch and Tony Wigram; foreword by Barbara L. Wheeler. London; Philadelphia: Jessica Kingsley.

Wigram, T., Bonde, L., Pedersen, I., \& ProQuest. (2002). A comprehensive guide to music therapy: Theory, clinical practice, research and training / Tony Wigram, Inge Nygaard Pedersen and Lars Ole Bonde. London: Jessica Kingsley.

Wigram, T. (2004). Improvisation: Methods and Techniques for Music Therapy Clinicians, Educators, and Students. London: Jessica Kingsley Publishers.

Winnicott, D. (1960). The theory of the parent-child relationship, International Journal of Psychoanalysis, 41. 585-595.

Winnicott, D. W. (1971). Playing and Reality. London: Penguin. 
Appendices 


\title{
Appendix A - Facility Information Sheet
}

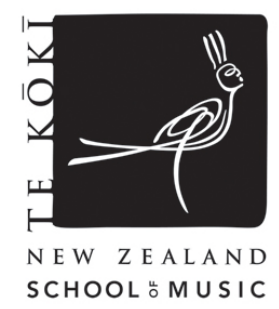

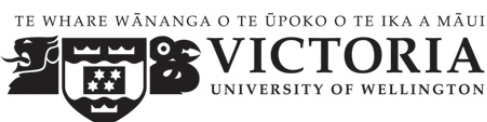

\section{MUSIC THERAPY RESEARCH}

Facility Information Sheet

\section{Making choices: exploring the different music therapy approaches utilised within a wide range of clients in various clinical settings.}

\author{
Principle Researcher - Wei-kai Shyu / [email] \\ Clinical Supervisor - [name] / [email]

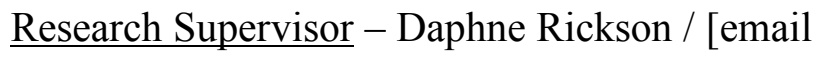

\section{Project description}

This research is being undertaken at the [name of facility] as part of a Masters in Music Therapy degree under the supervision of Daphne Rickson, Senior Lecturer of Music Therapy at the Victoria University of Wellington.

For this research study, I will exploring the different approaches I draw on in music therapy, how these approaches have influenced me in my ongoing journey as a student music therapist, and helped me decide the ways of working which might be best for me as a practitioner. During my practice over the past month I have noticed that different music therapists use very distinct approaches and methods in their practice, and that is likely to be influenced by the population they are working with and the contexts in which they are practicing; thus, I aim to investigate the significance of particular music therapy approaches for my clinical practice and to determine which of those approaches are most congruent to my ways of practice as a music therapist. Engaging in this research will improve my learning, and the findings will provide insight to guide music therapy practice with a diverse range of client populations in various settings 


\title{
What does this mean for the facility?
}

Because this research will use need to use existing data which includes video footage, clinical notes, and a reflective journal gathered during the time at the placement facility, I will need to request permission to perform research at this facility. Any data collected including photos, audio recordings, video recordings, reflective notes will be stored in a password-protected computer or on site at the facility. Clinical and self-reflective notes will be stored at the facility and/or on my personal laptop.

All steps will be taken to ensure confidentiality of the facility and its staff and clients. No real names will be used. However, it is acknowledged that the music therapy communities are small and there is a very slight possibility that the facility or any of the participants may be identified.

\section{Your Rights}

You are under no obligation to consent to this research. If you decide to disapprove, you may address this directly to Dr. Daphne Rickson. If you choose to approve consent to this research, you can:

- ask any questions about the research at any time until it is completed;

- change your mind about consent, provided that I am notified before Oct $30^{\text {th }} 2017$;

- have full access to the completed research study;

If you have any further questions, please feel free to contact me or my supervisor(s) via email provided.

\author{
Wei-kai Shyu \\ Student Music Therapist and Primary Researcher
}

\section{Ethical Approval}

This project has been reviewed and approved by the New Zealand School of Music Postgraduate Committee. The VUW Human Ethics Committee has given generic approval for music therapy students to conduct studies of this type. The music therapy projects have been judged to be low risk and, consequently, are not separately reviewed by any Human Ethics Committees. The supervisor named below is responsible for the ethical conduct of this research. If you have any concerns about the conduct of the research, please contact the supervisor or, if you wish to raise an issue with someone other than the student or supervisor, please contact the Victoria University of Wellington Humans Ethics Convener Associate Professor Susan Corbett via email susan.corbett@vuw.ac.nz / telephone +64-4-463 5480. 


\title{
Appendix B - Client Information Sheet
}

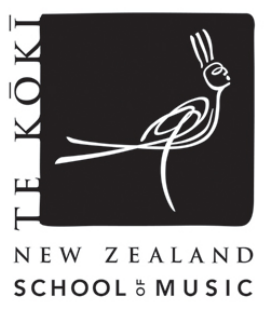

TE WHARE WĀNANGA O TE ŨPOKO O TE IKA A MĀUI

59 菌

\section{MUSIC THERAPY RESEARCH}

\section{Making choices: exploring the different music therapy approaches utilised within a wide range of clients in various clinical settings.}

\author{
Principle Researcher - Wei-kai Shyu / [email] \\ Clinical Supervisor - [name] / [email]

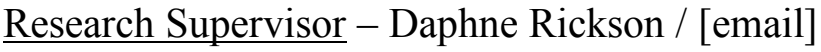

\section{Project description}

This research is being undertaken at the [name of facility] as part of a Masters in Music Therapy degree under the supervision of Daphne Rickson, Senior Lecturer of Music Therapy at the Victoria University of Wellington.

For this research study, I will exploring the different approaches I draw on in music therapy, how these approaches have influenced me in my ongoing journey as a student music therapist, and helped me decide the ways of working which might be best for me as a practitioner. During my practice over the past month I have noticed that different music therapists use very distinct approaches and methods in their practice, and that is likely to be influenced by the population they are working with and the contexts in which they are practicing; thus, I aim to investigate the significance of particular music therapy approaches for my clinical practice and to determine which of those approaches are most congruent to my ways of practice as a music therapist. Engaging in this research will improve my learning, and the findings will provide insight to guide music therapy practice with a diverse range of client populations in various settings

Engaging in this research will improve my learning, and the findings will provide insight to guide music therapy practice with a diverse range of client populations in various settings. This research will use existing data that includes video footage, clinical notes, and a reflective journal gathered during the time at the [name of facility]. Any data collected including photos, audio recordings, video recordings, reflective notes will be stored in a password-protected computer or on site at the facility. Clinical and self-reflective notes will be stored at the facility and/or on my 
personal laptop. All steps will be taken to ensure confidentiality of your child. No real names will be used. However, it is acknowledged that the music therapy communities are small and there is a very slight possibility that participants may be identified.

\title{
Completion of Research
}

After my research is completed and graded, it will be available for people to look at through the Victoria University of Wellington library and online database. I will present my research in private to my examiners, and may discuss it with other staff at the facility or with my fellow students also carrying out their research project. All research data on my laptop will be cleared after my final thesis grading and the data stored on site at the facility will remain under the property of the facility and stored securely for a further period of ten years.

\section{Participant's Rights}

You are under no obligation to consent to this research. If you decide to disapprove, you may address this directly to the Clinical Services Manager. If you choose to approve consent to this research, you can:

- ask any questions about the research at any time until it is completed;

- change your mind about consent, provided that I am notified before Oct $30^{\text {th }} 2017$;

- have full access to the completed research study;

If you have any further questions, please feel free to contact me or my supervisor(s) via email provided.

\author{
Wei-kai Shyu \\ Student Music Therapist and Primary Researcher
}

\section{Ethical Approval}

This project has been reviewed and approved by the New Zealand School of Music Postgraduate Committee. The VUW Human Ethics Committee has given generic approval for music therapy students to conduct studies of this type. The music therapy projects have been judged to be low risk and, consequently, are not separately reviewed by any Human Ethics Committees. The supervisor named below is responsible for the ethical conduct of this research. If you have any concerns about the conduct of the research, please contact the supervisor or, if you wish to raise an issue with someone other than the student or supervisor, please contact the Victoria University of Wellington Humans Ethics Convener Associate Professor Susan Corbett via email susan.corbett@vuw.ac.nz / telephone +64-4-463 5480. 


\section{Appendix C - Consent Form}

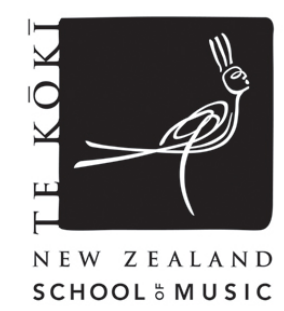

E WHARE WĀNANGA O TE ŨPOKO O TE IKA A MĀUI

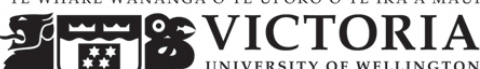

** $\cdots$.

\section{MUSIC THERAPY RESEARCH}

Making choices: exploring the different music therapy approaches utilised within a wide range of clients in various clinical settings.

\section{PLEASE TICK AS APPROPRIATE}

I have read the information sheet provided for the research project titled above and acknowledge the details of the study. My questions have been answered to my satisfaction, and I understand that I may ask further questions at any time.

I understand that it is my choice to be included in the research project and that I may withdraw from the study at any time provided I notify the researcher by Oct $30^{\text {th }} 2017$.

I understand that any information relating to my participation in the research project is confidential and that no material that could identify me will be used in any reports in this research project.

I understand that the research project will be stopped if it should appear harmful to me.

I have had time to consider whether I want to anonymously be included in this study.

I know whom to contact if 1 have any questions or concerns regarding the research project. 
I understand that the research project will be presented by the researcher as a thesis towards the qualification of Master of Music Therapy at the Victoria University of Wellington.

I wish to receive a copy of the research project. Circle YES/NO

$\mathrm{I}$, ............................................... (full name of participant) hereby give consent to be included in the proposed research study.

Signature:

Date:

\author{
Wei-kai Shyu \\ Student Music Therapist and Primary Researcher \\ Email: \\ Phone:
}

\title{
Ethical Approval
}

This project has been reviewed and approved by the New Zealand School of Music Postgraduate Committee. The VUW Human Ethics Committee has given generic approval for music therapy students to conduct studies of this type. The music therapy projects have been judged to be low risk and, consequently, are not separately reviewed by any Human Ethics Committees. The supervisor named below is responsible for the ethical conduct of this research. If you have any concerns about the conduct of the research, please contact the supervisor or, if you wish to raise an issue with someone other than the student or supervisor, please contact the Victoria University of Wellington Humans Ethics Convener Associate Professor Susan Corbett via email susan.corbett@vuw.ac.nz / telephone +64-4-463 5480. 


\section{Appendix D - Data Analysis}

\begin{tabular}{|c|c|c|c|c|c|}
\hline$\Delta$ & $\bar{A}$ & B & C & $\overline{D D}$ & $\bar{E}$ \\
\hline 1 & & Reflective notes/Context & Raw Data: Clinical notes & $\begin{array}{l}\text { Interrogation/Interpretation of what was } \\
\text { happening in terms of APPROACH }\end{array}$ & Code \\
\hline 2 & Session \#01 $(28 / 01 / 17)$ & $\begin{array}{l}\text { Transition period with T. I wasn't sure what to expect } \\
\text { but as a first session, the feacal smearing really threw } \\
\text { me off guard for a bit. During the session, Itried to be } \\
\text { as engaging as I could. Found myself trying to fill the } \\
\text { gaps of silence with music, ie. during indexing, I saw } \\
\text { ) myself playing at many 'unnecessary' moments. M } \\
\text { asked me why I played each moment - and to be } \\
\text { honest, I had no idea why. I I vuess I was uncomfortable } \\
\text { with the silence and being 'Idling' doing nothing. I } \\
\text { wanted to make myself as resourceful and useful as I } \\
\text { could. }\end{array}$ & $\begin{array}{l}\text { We began with a greeting song in which Jesse sat down with us while we sang it to him. I showed many signs of social engagement } \\
\text { by holding hands with me, the other therapists, and also reciprocating with my hiffive. He was able to make independent decisions } \\
\text { such as choosing to leave the room and come back into the room. Right before the incident, I played a 4-chord progression on the } \\
\text { guitar while Tand M M linked hands with J. He walked over to the window and looked out ofit (he was perhaps deep in thoughtl). } \\
\text { Jesse's session was truncated by some faecal smearing that happened near the } 30 \text {-minute mark. After the cleaning, we brought } \\
\text { Jesse back to the room to sing a goodbye song, in which he chose to sit on the floor. He rocked back and forth a bit and then for } \\
\text { lightly banged his head a few times on the carpet flloor. The session ended after the goodbye song. }\end{array}$ & $\begin{array}{l}\text { Took the lead with greeting song - client joined us } \\
\text { shortly after. Alternated roles with main therapist. } \\
\text { Improvised. Matched client on guitar. Remained on } \\
\text { the 'peripheral'. Tried redirection of } \\
\text { unwanted/destructive behaviours. Session came to } \\
\text { close after incident. }\end{array}$ & Music-centered \\
\hline 3 & Session \#01 $(28 / 01 / 17)$ & & 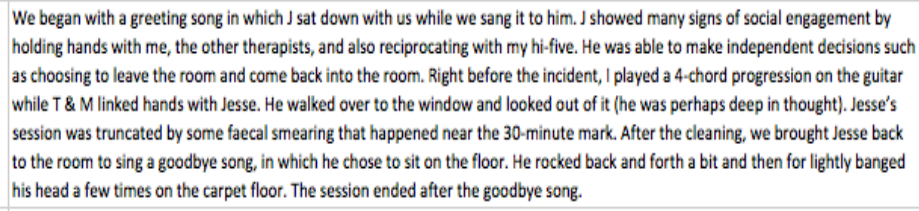 & $\begin{array}{l}\text { Took the lead with greeting song - client joined us } \\
\text { shortly after. Alternated roles with main therapist. } \\
\text { Improvised. Matched client on guitar. Remained on } \\
\text { the 'peripheral'. Tried redirection of } \\
\text { unwanted/destructive behaviours. Session came to } \\
\text { close after incident. }\end{array}$ & Behavioural \\
\hline 4 & Session \#02 (04/02/17) & 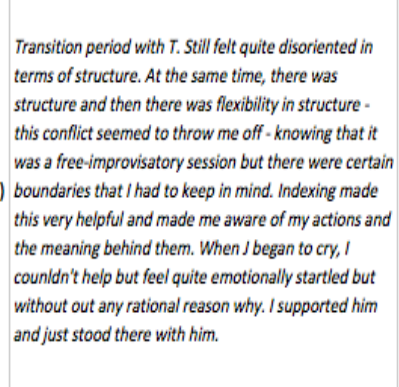 & 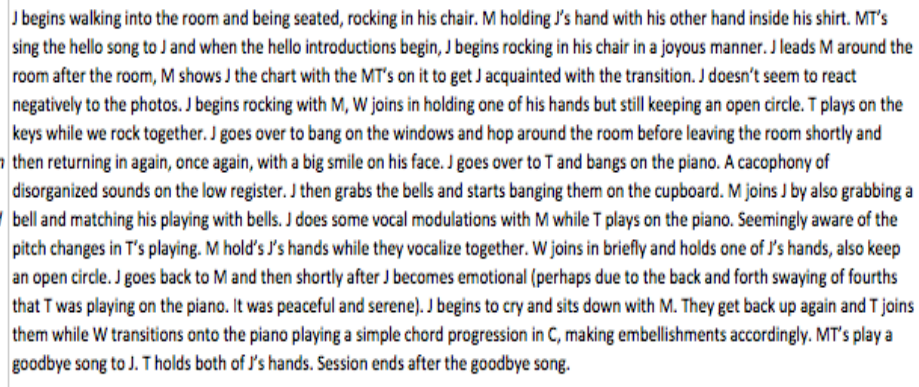 & $\begin{array}{l}\text { Began session with greeting song, taking the lead. } \\
\text { Improvised client movements/painting a musical } \\
\text { portrait of client. Allows client to be explorative } \\
\text { without any fixed boundaries. Remained observant } \\
\text { and on the peripheral - following M's lead. Matched } \\
\text { client musically. Contained client during emotional } \\
\text { 'catharsis' and provided a warm and accepting } \\
\text { musical atmosphere.. }\end{array}$ & Music-centered \\
\hline 5 & Session \#02 (04/02/17) & & 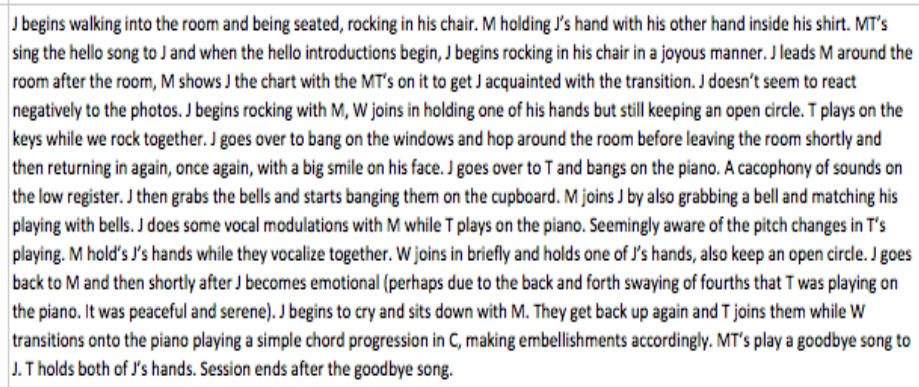 & $\begin{array}{l}\text { Began session with greeting song, taking the lead. } \\
\text { Improvised client movements/painting a musical } \\
\text { portrait of client. Allows client to be explorative } \\
\text { without any fixed boundaries. Remained observant } \\
\text { and on the peripheral - following M's lead. Matched } \\
\text { client musically. Contained client during emotional } \\
\text { 'catharsis' and provided a warm and accepting } \\
\text { musical atmosphere. }\end{array}$ & Humanistic \\
\hline
\end{tabular}




\section{Appendix E - Thematic Analysis}

\begin{tabular}{|c|c|c|c|c|c|c|c|}
\hline 马 & A & B & $c$ & $D$ & $\mathrm{t}$ & $\mathrm{F}$ & c \\
\hline 1 & & Refective notes/Context & Raw Dota: Clinical notes & $\begin{array}{l}\text { Interrogation/Interpretation of what was } \\
\text { happening in terms of APPROACH }\end{array}$ & Code 1 & Theoretical Perspectives & CooE 2 [Keyword/What w was doing] \\
\hline 2 & Session $102(00 / 02 / 17)$ & 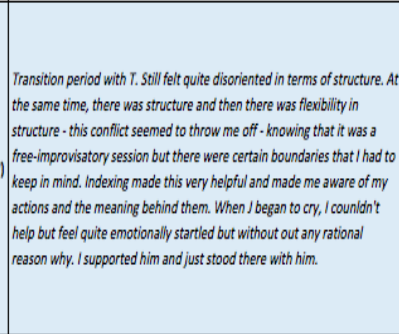 & 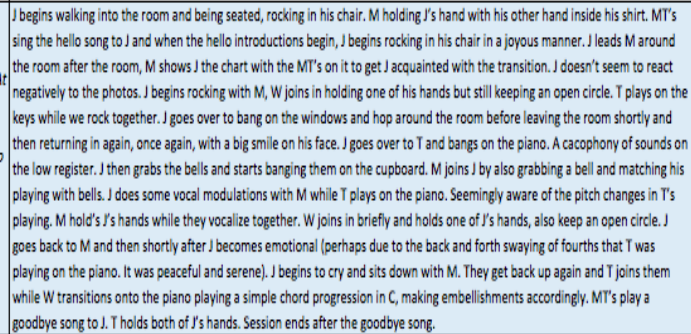 & 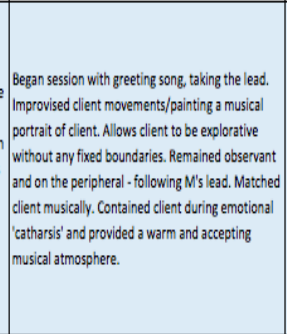 & de Paychoodnamic & 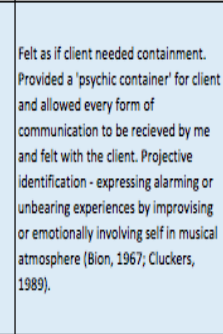 & Hoding \\
\hline 3 & Seession H05 $(25 / 02 / 17)$ & 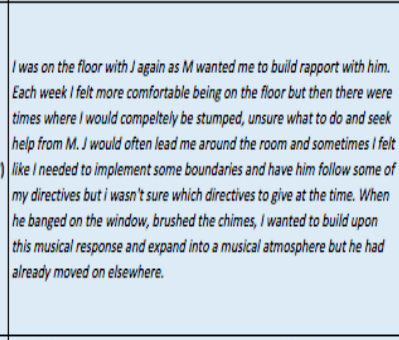 & 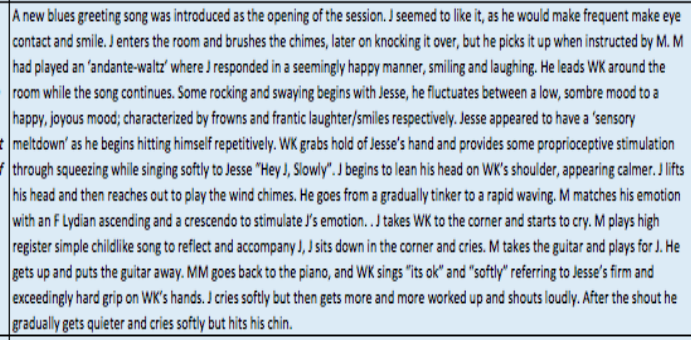 & 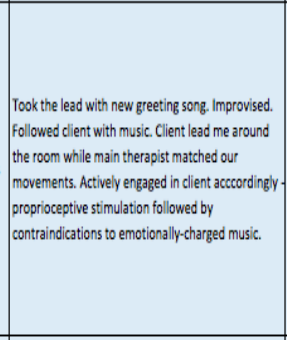 & Psychodynamic & 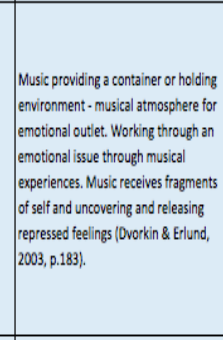 & 5 Hoding \\
\hline 4 & Session tog $_{225 / 03}$ & 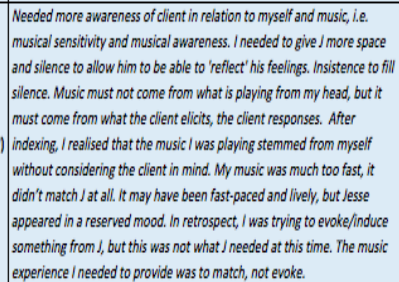 & 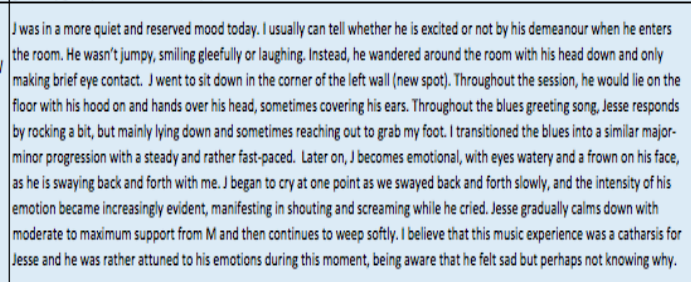 & 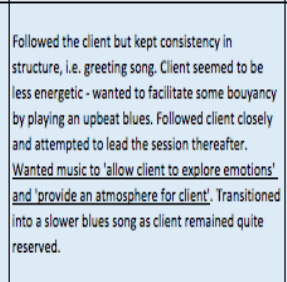 & Psychodynamic & 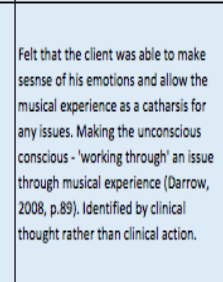 & Holding \\
\hline 5 & $\begin{array}{l}\text { Session \#07 } \\
(31 / 05 / 177)\end{array}$ & 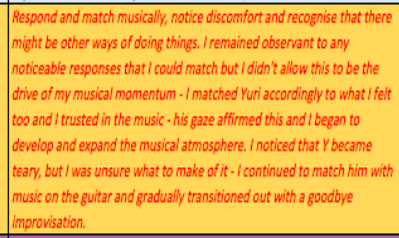 & 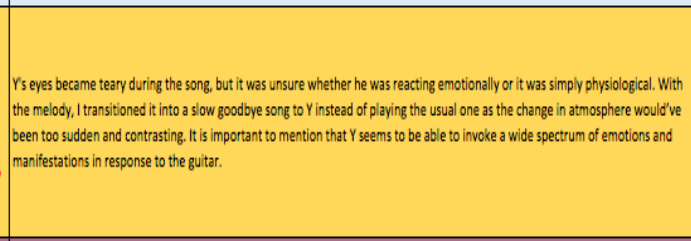 & 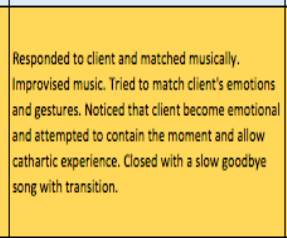 & Psychoodynamic & 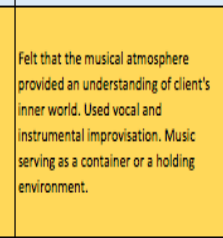 & Hoding \\
\hline 6 & Session $\mathrm{A} 4(24 / 02 / 17)$ & 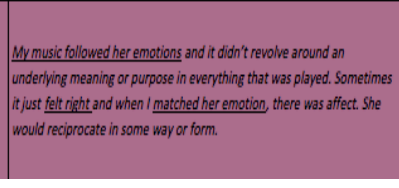 & 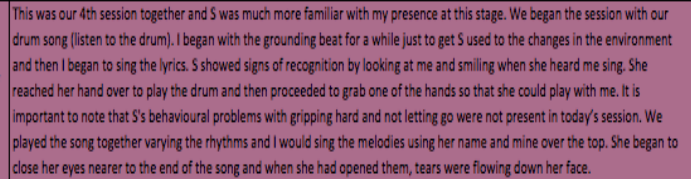 & 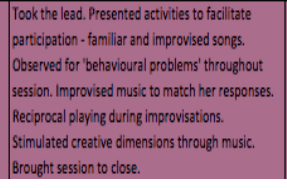 & Psychoodynamic & 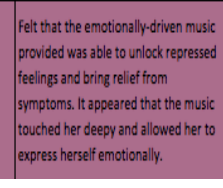 & ing \\
\hline
\end{tabular}




\section{Appendix F - Example of Clinical Notes}

\begin{tabular}{|c|c|c|}
\hline \multicolumn{2}{|c|}{ Long-term goal } & $\begin{array}{c}\text { Short-term objectives } \\
\text { (may be specific objectives or broad areas for development) }\end{array}$ \\
\hline 1) $\mathrm{s}$ & $\begin{array}{l}\text { Il develop improved } \\
\text { rpersonal relationships } \\
\text { social skills. }\end{array}$ & $\begin{array}{l}\text { a) S will engage in alternating musical play with the therapist } \\
\text { on four consecutive occasions with mild prompting. } \\
\text { b) S will follow verbal directives and/or musical cues in order } \\
\text { to engage in social interactions (such as greetings, turn } \\
\text { taking and shared instrument play) with moderate } \\
\text { prompting on four consecutive occasions. }\end{array}$ \\
\hline DATE & Progress & COMMENTS \\
\hline $\begin{array}{l}03 / 02 / 17 \\
\text { SESSION } \\
1\end{array}$ & $\begin{array}{l}\text { Observation and co- } \\
\text { therapy with } X\end{array}$ & $\begin{array}{l}\text { S seemed to respond very well to rhythm and would often reach out her } \\
\text { hand. She would grip very tightly without letting go and many times } X \text { had to } \\
\text { remove her hand with slight force. We moved to the piano where she } \\
\text { continued to reach out to grab } X \text { but he would redirect her hands to the } \\
\text { piano. }\end{array}$ \\
\hline $\begin{array}{l}10 / 02 / 17 \\
\text { SESSION } \\
2\end{array}$ & & $\begin{array}{l}\text { This session took place in her room. I sat in front of her nearer to her side so } \\
\text { that she had accessibility to play the guitar if she needed. We began our } \\
\text { greeting song and she responded to it by immediately reaching over to strum } \\
\text { the guitar with the support of my hand. Her rhythms were very consistent } \\
\text { and accurate in a steady } 4 / 4 \text { manner and she was able to have flexibility in } \\
\text { increasing and decreasing tempo and speed. During the chorus of 'Hey Jude', } \\
S \text { was able to make vocalizations, although very sporadic and short. I echoed } \\
\text { and then matched her singing. In the goodbye song, S would begin to vocalise } \\
\text { with me in a call-and-response manner, although very brief. There seemed to } \\
\text { be some vocal modulation, as she appeared to be in the same pitch as me. }\end{array}$ \\
\hline $\begin{array}{l}17 / 02 / 17 \\
\text { SESSION } \\
3\end{array}$ & & $\begin{array}{l}\text { This was our 4th session together and S was much more familiar with my } \\
\text { presence at this stage. We began the session with our drum song (listen to } \\
\text { the drum). I began with the grounding beat for a while just to get } S \text { used to } \\
\text { the changes in the environment and then I began to sing the lyrics. S showed } \\
\text { signs of recognition by looking at me and smiling when she heard me sing. } \\
\text { She reached her hand over to play the drum and then proceeded to grab one } \\
\text { of the hands so that she could play with me. It is important to note that } S \\
\text { behavioural problems with gripping hard and not letting go were not present } \\
\text { in today's session. We played the song together varying the rhythms and I } \\
\text { would sing the melodies using her name and mine over the top. She began to } \\
\text { close her eyes nearer to the end of the song and when she had opened them, } \\
\text { tears were flowing down her face. }\end{array}$ \\
\hline $\begin{array}{l}24 / 02 / 17 \\
\text { SESSION }\end{array}$ & & $\begin{array}{l}\text { Before our session officially began, I went to shake her hand but } \mathrm{S} \text { displayed } \\
\text { defensiveness and put her hands together on her torso. Our session began } \\
\text { with a greeting song where } \mathrm{S} \text { responded with excitement and joy, laughing } \\
\text { and smiling while strumming the guitar with her hand gripped on mine... }\end{array}$ \\
\hline
\end{tabular}




\section{Appendix G - Example of Goal Sheet}

\section{Music therapy goals and focus areas}

Date: 27th March 2017

Name: Dylan

DoB: XX.XX.XXXX Student Music Therapist: Wei-kai

\begin{tabular}{|c|c|c|}
\hline & Long-term goal & $\begin{array}{l}\text { Short-term focus } \\
\text { (may be specific objectives or } \\
\text { broad areas for development) }\end{array}$ \\
\hline & $\begin{array}{l}\text { Dylan will develop } \\
\text { improved } \\
\text { communication skills. }\end{array}$ & $\begin{array}{l}\text { a. Dylan will utilise picture symbols, gestures, sign language and/or } \\
\text { vocalizations to communicate his wants in the music therapy session } \\
\text { with minimal prompting on four consecutive occasions. } \\
\text { b. Dylan will follow verbal directives and/or musical cues in order to } \\
\text { engage in social interactions (such as greetings, turn taking and } \\
\text { shared instrument play) with minimal prompting on four } \\
\text { consecutive occasions. }\end{array}$ \\
\hline 2. & $\begin{array}{l}\text { Dylan will develop and } \\
\text { demonstrate improved } \\
\text { attention. }\end{array}$ & $\begin{array}{l}\text { a. Dylan will actively participate in each musical activity presented with } \\
\text { minimal prompting on four consecutive occasions. } \\
\text { b. Dylan will maintain sustained instrument play during structured } \\
\text { musical activities with moderate prompting on four consecutive } \\
\text { occasions. }\end{array}$ \\
\hline \multicolumn{3}{|c|}{ Notes: } \\
\hline
\end{tabular}

